University of Rhode Island

DigitalCommons@URI

Open Access Master's Theses

2004

\title{
GLOBAL CLIMATE CHANGE AND SHIFTING SEA ICE: PLANNING FOR NEW FISHERY DEVELOPMENT IN THE ARCTIC
}

Kimberly Anne Lellis

University of Rhode Island, klellisdibble@gmail.com

Follow this and additional works at: https://digitalcommons.uri.edu/theses

\section{Recommended Citation}

Lellis, Kimberly Anne, "GLOBAL CLIMATE CHANGE AND SHIFTING SEA ICE: PLANNING FOR NEW FISHERY DEVELOPMENT IN THE ARCTIC" (2004). Open Access Master's Theses. Paper 128.

https://digitalcommons.uri.edu/theses/128

This Thesis is brought to you for free and open access by DigitalCommons@URI. It has been accepted for inclusion in Open Access Master's Theses by an authorized administrator of DigitalCommons@URI. For more information, please contact digitalcommons-group@uri.edu. 
GLOBAL CLIMATE CHANGE AND SHIFTING SEA ICE:

PLANNING FOR NEW FISHERY DEVELOPMENT IN THE ARCTIC

BY

KIMBERLY ANNE LELLIS

A THESIS SUBMITTED IN PARTIAL FULFILLMENT OF THE

REQUIREMENTS FOR THE DEGREE OF

MASTER OF ARTS

IN

MARINE AFFAIRS

UNIVERSITY OF RHODE ISLAND

2004 
MASTER OF ARTS THESIS

OF

KIMBERLY ANNE LELLIS

\section{APPROVED:}

Thesis Committee:

Major Professor

DEAN OF THE GRADUATE SCHOOL

UNIVERSITY OF RHODE ISLAND

2004 


\begin{abstract}
This thesis examines the implications of global warming for fisheries management in the Arctic waters off Alaska. In particular, the purpose of this thesis is to ascertain the current level of awareness, concern, and planning by physical scientists, social scientists, and federal and state resource managers for a potential future scenario that could develop in Alaska if: 1) warming ocean temperatures cause an expansion or a shift in the ranges of commercial fish species; and 2) the retreat of sea ice due to climate change allows commercial fishing fleets to expand into new areas such as the Chukchi Sea. Commercial fishing in this Sea could be problematic because at the current time, there are no federal Fishery Management Plans for species residing in the Chukchi Sea. Fishery managers in Alaska do not appear to be planning for future fisheries management in the Chukchi Sea, even though the scientific community has stated that the Arctic could soon become ice-free, with distributional shifts in species likely. The data used in this thesis research were collected from a series of interviews to determine: 1) if planning should be done to prepare for new commercial fisheries development in the Chukchi Sea; 2) what future management would look like in the Chukchi Sea; and 3) how Chukchi Sea Natives could be both affected by and involved in the management of new fish stocks. Results show that fishery managers would not plan for fishery shifts or practice proactive fisheries management. Results also show that the Community Development Quota program could be used to involve Alaska Natives in making management decisions. However, co-management of fishery resources may be a better option in the long run.
\end{abstract}




\section{Acknowledgements}

This work is dedicated to my parents, William and Kathryn, and my sister Christine. I would have been lost without your guidance. I would also like to thank Carolynn Box, Misty Hamilton, Kristina Perrelli, and Scott McCue for their support throughout the past two years.

Many thanks go to Seth Macinko, Dennis Nixon, Tom Rossby, and Igor Belkin for their expertise and patience during the research process. I would especially like to thank Seth Macinko for being such a wonderful advisor throughout my graduate studies at the University of Rhode Island and for helping me get the grant that allowed me to do this thesis research. 


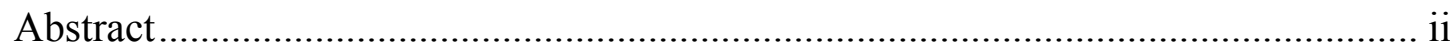

Acknowledgements.......................................................................................... iii

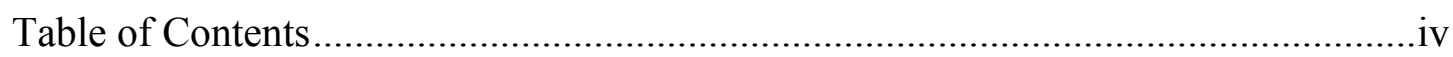

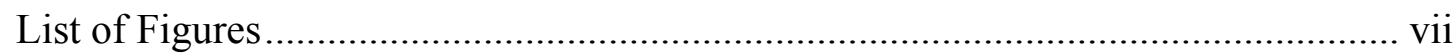

Chapter 1: Introduction and Research Methods ..........................................................

Research Methods...........................................................................

Chapter 2: Physical and Biological Change in the Bering and Chukchi Seas.............11

Historic Evidence of Climate Change in the Arctic ...................................11

Current Evidence of Climate Change in the Arctic ...................................13

Diminishing Sea Ice due to Climate Change..............................................18

Evidence for Fishery Shifts in the Atlantic Ocean due to Warming

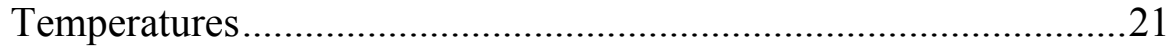

Evidence for Fishery Shifts in the Pacific Ocean due to Warming

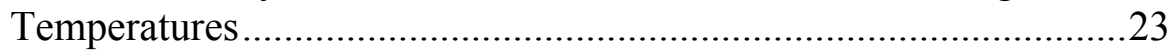

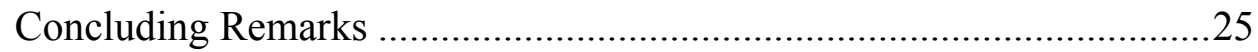

Chapter 3: Alaska Natives of the Chukchi Sea..........................................................27

Background on Alaska Natives in the Chukchi Sea Region......................27

Climate Change and Alaska Natives ……………………......................29

Climate Change, Alaska Natives, and New Commercial Fisheries Development ..............................................................................

Chapter 4: Institutional Structure of Fisheries Management in the Bering and Chukchi Seas 36

Federal Fisheries Management in the Bering Sea ....................................38 
Federal Management of Commercial Fisheries in Bering Sea...38

Federal Management of Subsistence Fisheries in Bering Sea ....42

State Fisheries Management in the Bering Sea

State Management of Commercial Fisheries in Bering Sea.......43

State Management of Subsistence Fisheries in Bering Sea ........44

International Fisheries Management in the Bering Sea ..........................45

Future Fisheries Management Directions in the Chukchi Sea.................45

Chapter 5: Results.

Section I: What do Physical Scientists Think?

What will the Arctic Alaskan climate be like in the coming decades?

Is the current warming trend and retreat of sea ice due to natural or anthropogenic causes, and will this trend continue in the coming years?

Should planning be underway to prepare for northward shifts in commercial fish species? ..............................................54

Section II: What do Social Scientists Think? ......................................56

Current Alaska Native Issues ...............................................57

Will Alaska Natives be affected by commercial fishing fleets moving into northern areas due to shifting fisheries and climate change? If so, how?

How do you think Alaska Natives could be involved in the management process for developing fisheries in new areas such as the Chukchi Sea?

Section III: What do Fishery Managers Think?

Subsection A: Planning for Fisheries Expansion.....

Subsection B: Future Fisheries Management in the Chukchi

$\underline{\text { Sea. }}$. 
What should fisheries management look like in a new region such as the Chukchi Sea?

Who should oversee the management of fisheries shifting into the Chukchi Sea?

Should a proactive management regime be put in place prior to exploratory fishing?

\section{Subsection C: The Effects of Fishery Development on Coastal}

Chukchi Sea Communities

Effects of Commercial Fisheries Development on Alaska

Natives

Involvement of Natives in Fisheries Management in the Chukchi Sea

Conclusion

Chapter 6: Summary of Research Results, Discussion, Recommendations, and Conclusion.

Summary of Research Results

Planning for the Implications of Climate Change in the Chukchi Sea ....82

Future Involvement of Alaska Natives in Fisheries Management in the Chukchi Sea

Recommendations

Conclusion

Appendix A: National Standards for fishery conservation and management mandated by the MSFCMA

Bibliography 


\section{List of Figures}

Figure

Figure 1. Northern Hemisphere Temperature Histories..........................................12

Figure 2. Western Alaska Sockeye Salmon Response to the 1979 Regime Shift .14

Figure 3. Ocean Heat Content of the North Pacific Ocean .....................................15

Figure 4. Predicted Annual Mean Surface Air Temperature Increases ..................17

Figure 5. Winter Percent Ice Cover for the Bering and Chukchi Seas ..................20

Figure 6. Exclusive Economic Zone off the United States ....................................40 


\section{Chapter 1}

Introduction and Research Methods

The response of marine resources to changing climate is very difficult to predict but northward migrations are likely. In particular, northward movement of Bering Sea species into the Beaufort/Chukchi Sea region north of Bering Strait is likely. Climate warming is likely to bring extensive fishing activity to the Arctic, particularly in the Barents Sea and Beaufort/Chukchi region where commercial operations have been minimal in the past. In addition, Bering Sea fishing opportunities will increase as sea ice cover begins later and ends sooner in the year (Whitney et al. 2001; p. 3 of Appendix A).

What are the implications of global warming for fisheries management in the Arctic regions off Alaska and what level of preparations exist for confronting these implications? This thesis examines this question. Specifically, the purpose of this thesis is to ascertain the current level of awareness, concern, and planning by physical scientists, social scientists, and federal and state resource managers for a potential future scenario that could develop in Alaska if: 1) warming ocean temperatures cause an expansion $^{1}$ or a shift ${ }^{2}$ in the ranges of commercial fish species; and 2) the retreat of sea ice due to climate change allows commercial fishing fleets to expand into new areas such as the Chukchi Sea. Such an expansion in the range of commercial fishing activity could pose a problem because there are currently no federal Fishery Management Plans (FMP's) that cover commercial fisheries in the Chukchi Sea.

\footnotetext{
${ }^{1}$ An expansion in range means that a portion of the fish population remains in their current location while the other portion expands into new areas as new habitat opens due to climate change.

${ }^{2}$ A shift in range means that habitat at the current location would no longer be suitable for the fish species, and the entire population would shift into a new area. In the case of global warming, either a shift or an expansion could occur.
} 
At first impression, it would appear that there is little planning for, or recognition of, the potential effects of climate change on Arctic fisheries. On the other hand, as the opening quotation presented above demonstrates, U.S. military planners appear to have formed an unambiguous position regarding the potential future challenges. Thus, there seems to be a disconnect between the strategic assessments emanating from the fisheries community (broadly construed) and those from the military. In essence, this thesis seeks to examine the question of strategic planning within the fisheries community (relative to climate change in the Arctic) in greater depth than that provided by this first impression.

The opening quotation was taken from the proceedings of a symposium on "Naval Operations in an Ice-Free Arctic," convened in 2001 by the U.S. Office of Naval Research, Naval Ice Center, Oceanographer of the Navy, and the Arctic Research Commission (Whitney et al. 2001). ${ }^{3}$ The Navy report highlights the fact that if global warming continues to warm the Arctic, sea lanes could open by 2015, summer ice cover could completely disappear by 2050 , and shipping and commercial fishing could develop in the Arctic. The report recognizes that the U.S. Navy does not have the ships, technology, training, and logistics in place to patrol and police the U.S. Exclusive Economic Zone (EEZ) in the Arctic for defense, homeland security, or enforcement of fishing activities. The Navy report also highlights the fact that planning should be done now to prepare for new commercial activity in the Arctic, and that policy concerns should be addressed prior to the development of the Arctic region (Whitney et al. 2001).

\footnotetext{
${ }^{3}$ This footnote acknowledges the late discovery of the Navy report AND a general lack of knowledge of the Navy report by those involved in the fisheries world.
} 
The number of ice-free days in the Arctic has been steadily increasing (Comiso 2002), so commercial fishing may begin in the Arctic in the coming years. Given that there are currently no federal Fishery Management Plans (FMP's) that cover commercial fisheries in the Chukchi Sea, fishery managers have the choice to either manage proactively or reactively if fish shift into the Chukchi Sea in the future. Past fisheries management decisions in other regions have been made reactively after fishing has commenced, often resulting in overfishing of the fish stock. However, if commercial fish shift into the Chukchi Sea, it would be the first time in many years that a proactive plan could be developed prior to the inception of commercial fishing.

The Navy has found some merit in calling for both planning and policies to mitigate the effects of a future ice-free Arctic. If anything like the Navy scenario came to pass, the implications would be profound. Therefore, the purpose of this thesis research is to interview physical scientists, social scientists, and fishery managers to determine:

1) If there should be any planning for new commercial fisheries development in the Chukchi Sea, and if so, the type of planning that should be done prior to development.

2) How this development should be managed, who should oversee this management, and if this management should be proactively developed and put in place prior to commercial fisheries development.

3) If Alaska Natives would be affected by new commercial fisheries development, how Natives could be involved the management of new fish 
stocks shifting into the Chukchi Sea, and who should be involved in this new management.

To gather this information, two conferences were attended and a series of interviews were conducted with state and federal fishery managers. The conferences provided information on the current and potential future state of sea ice in the Arctic, warming temperatures, and climate change impacts on Alaska Natives in the Bering Sea region. The interviews with federal and state resource managers documented the current level of awareness, concern, and planning for Arctic fisheries expansion by fishery managers, documented what future fisheries management regime would be appropriate (in their opinions) for the Chukchi Sea, documented how Alaska Natives could be affected by new commercial fisheries development, and how they could be involved in fisheries management decisions. This information provides the basis for the discussion presented in Chapter 6. The research methodology used to gather this thesis data will be further explained in the next section.

\section{Research Methods}

Two conferences were attended in May 2004 and a series of interviews were conducted to gather data for this thesis. In total, thirty-one people were interviewed. Of these thirty-one people, twenty-one informal interviews ${ }^{4}$ were conducted and ten

\footnotetext{
${ }^{4}$ Informal interviews are defined as informal conversations where questions were asked relevant to the respondents' expertise. At the Arctic Research Consortium of the United States (ARCUS) Sixteenth Annual Meeting and Arctic Forum, eleven informal interviews were conducted. At the $5^{\text {th }}$ International Congress of Arctic Social Sciences (ICASS V) conference, ten informal interviews were conducted.
} 
formal interviews ${ }^{5}$ were conducted. This is a small sample size; however, this thesis research is exploratory in nature and therefore did not require a large number of respondents. This research was funded by a Small Grant for Exploratory Research (SGER) from the National Science Foundation. Exploratory research is defined as research that has never been carried out on a particular subject. This thesis research is exploratory in nature because an extensive examination of the potential implications of climate change on fisheries management in the Bering and Chukchi Seas has not been conducted.

The two conferences attended were: 1) the Arctic Research Consortium of the United States (ARCUS) Sixteenth Annual Meeting and Arctic Forum held in Washington, D.C., 13-14 May, 2004; and 2) the $5^{\text {th }}$ International Congress of Arctic Social Sciences (ICASS V) conference held in Fairbanks, Alaska, 19-23 May 2004. The purpose of attending the two conferences and conducting informal interviews with attendees was twofold: 1) to clarify specific points made within conference presentations; and 2) to ask respondents specific research questions related to their expertise. The purpose for conducting the formal interviews was to pose seven research questions (listed on page 7) regarding planning and future fisheries management in the Chukchi Sea region. The data used in this thesis were compiled into three sections (Sections I, II, and III), and the results are presented in Chapter 5.

Sections I \& II pertain to the informal interviews conducted with attendees at the two conferences. Section I pertains to the ARCUS meeting in Washington, D.C. The focus of the ARCUS meeting was on the recent declining trend of sea ice in the

\footnotetext{
${ }^{5}$ Formal interviews are defined as formal sit-down sessions in which a predetermined series of seven research questions were asked.
} 
Arctic. At the sessions, knowledge was gained on the current and potential future state of sea ice in the Arctic. Informal interviews were conducted with eleven physical scientists. The results of the ARCUS presentations and the informal interviews with physical scientists will be analyzed in Section I of Chapter 5. The following three research questions were posed to the physical scientists:

1) What will the Arctic Alaskan climate be like in the coming decades?

2) Is the current warming trend and decline of sea ice in Alaska due to natural or anthropogenic causes? Will this trend in sea ice retreat reverse itself naturally in the coming years?

3) Should planning be underway to prepare for northward shifts in commercial fish species?

Section II pertains to the ICASS V conference attended in Fairbanks, Alaska. The theme of the ICASS V conference was "Local and Global Aspects of Arctic Social Systems." While in the sessions, knowledge was gained on the current issues faced by Alaska Natives. Informal interviews were conducted with ten social scientists. The results of the presentations and informal interviews conducted at the ICASS V meeting are analyzed in Section II of Chapter 5. The following two research questions were presented to social scientists at ICASS V:

1) Will Alaska Natives be affected by commercial fishing fleets moving into northern areas due to shifting fisheries and climate change? If so, how? 
2) How do you think Alaska Natives could be involved in the management process for developing fisheries in new areas such as the Chukchi Sea?

Section III pertains to the formal interviews conducted during May 24-28, 2004, in Anchorage and Juneau, Alaska. Formal sit-down interviews were conducted with ten federal and state resource managers and other knowledgeable persons involved in commercial and subsistence fisheries management in Alaska. The respondents were chosen based on their historic and current knowledge of the fisheries management system in Alaska. The respondents represented the following agencies, organizations, or universities: 1) North Pacific Fishery Management Council; 2) National Marine Fisheries Service; 3) Alaska Department of Fish and Game; 4) Norton Sound Economic Development Corporation; 5) University of Alaska, Anchorage; 6) University of Alaska, Fairbanks; and 7) the North Pacific Research Board. Due to the non-responsive nature of two respondents, the total sample size will be eight respondents. Each of the eight respondents was asked a series of seven questions (listed below). The results of these interviews were compiled and analyzed in Section III of Chapter 5. The following seven research questions were presented to the interviewees:

1. Given the current rate of global climate change, do you think fishery managers should be planning for shifts in species, and why do you feel this way?

2. If you believe that there should be planning, what type of planning should be done? 
3. If fisheries shift into new areas such as the Chukchi Sea (which could be a problem because the federal FMP's in place do not cover commercial fish species in the Chukchi Sea), how do you think this development should be managed, and who should oversee this management?

4. Should this management be developed prior to allowing fishing in those areas to control the amount and type of fishing done by fishermen that are exploring new areas?

5. If fisheries shift into new areas, do you think Native communities would be affected by the presence of commercial fishing fleets off their coasts?

6. How do you think Alaska Natives could be involved in the management process for developing fisheries in new areas such as the Chukchi Sea?

7. Who should be involved in this management?

Prior to the data analysis and discussion, background material will be provided in Chapters 2, 3, and 4 in order to build the case for the plausibility of an ice-free Arctic and the associated implications. Chapter 2 will review evidence of changes in the Bering and Chukchi Seas due to warming temperatures. This review will include historic and current evidence of climate change, the decrease in the extent and thickness of sea ice, and evidence of northward shifts in fisheries in both the Atlantic and the Pacific. This evidence supports the need for a proactive approach because it shows that the Bering and Chukchi Sea ecosystems are undergoing large-scale changes that are not accounted for in the current management regime for commercial 
fisheries off Alaska, and that the Navy's prediction for northward shifts of fish stocks into the Chukchi Sea may soon be realized.

Chapter 3 will present information on Alaska Natives off the Bering and Chukchi Seas and their relationship with the marine environment for the purpose of explaining how Native communities could be affected by new commercial fisheries development, and how these peoples could be involved in the management of fish stocks moving into the Chukchi Sea.

Chapter 4 will describe the current management of both commercial and subsistence fish harvests in the Bering and Chukchi Seas. If fishery managers choose to reactively manage fish stocks moving into the Chukchi Sea, it is likely that any new management in the Chukchi Sea will just be an extension of current management in the Bering Sea. However, if managers choose to manage proactively, the management will be developed prior to resource extraction and this proactive management could be an entirely new way of managing fisheries off Alaska. Therefore the institutional structure of fisheries management in the Bering Sea will be described, and the chapter will end with future management directions for the Chukchi Sea.

Chapter 5 will present results from the interviews and conferences in Washington, D.C. and Alaska. This chapter will highlight current planning and future directions for management in Arctic Alaskan waters.

Chapter 6 presents a discussion of planning steps that could be taken to avert overexploitation, options for future management in the Chukchi Sea, and the future involvement of Native communities in the management of developing fisheries in the 
Chukchi Sea. This chapter will conclude with recommendations for current fisheries managers as well as recommendations for future scientific research. 


\section{Chapter 2}

Physical and Biological Change in the Bering and Chukchi Seas

There have been many unusual occurrences in recent years [in our area]. Weather patterns, fish distributions, and other things are very odd. Some species of fish have been caught in areas where they've never been seen before. There used to be a lot of tomcod in our area, but no longer, and we don't know why...Animals, too, are going to places they've never been before. Is it lack of food- or because of other reasons? Salmon are decreasing in some places. They are fewer in the Yukon River now. There are fewer clams in our area. The bay used to have lots of clams, but now there are hardly any-only very small ones. And the shellfish have moved into our area, where they used not to be. -Dale T. Smith, Sr., Mekoryuk, Alaska. (Krupnik 2000b; p.40)

The purpose of this chapter is to present evidence of changing environments and ecosystems in the Bering and Chukchi Seas due to climate change to support the hypothesis that the situation outlined in Chapter 1 is real. Evidence is presented on historic and current changes in climate, the decrease in the extent and thickness of sea ice, and the northward shifts of fish populations in both the Atlantic and Pacific Oceans. This chapter will form the biological basis for the argument for a proactive plan to account for potential new fisheries shifts, which are not covered under the current fisheries management regime in the North Pacific Ocean. The first section of this chapter will review historic evidence of climate change in the Arctic.

Historic Evidence of Climate Change in the Arctic

The Earth has undergone large abrupt shifts in climate in the past (Alley et al. 2003). Considering the lack of long-term instrumental records of temperature (dated 
back more than a century and a half), scientists have to rely on various proxy data that help reconstruct past temperatures. Such proxy paleoclimate data are derived from deep ocean sediment microfossils, corals, ice cores, tree rings, fossil pollen, lake varves, speleothems (stalagmites/stalactites), borehole temperature records, and other sources (Mann 2003; NOAA 2004). These paleoclimate data have been instrumental in determining the extent, duration and magnitude of these climate changes. In the following figure (Fig. 1), data gathered from the use of proxies were plotted by Mann (2002). This figure shows two things: 1) temperature remained constant from 10001900 A.D. and then increased substantially in the past century; and 2) the proxies are consistent with each other because temperatures have increased in each proxy.

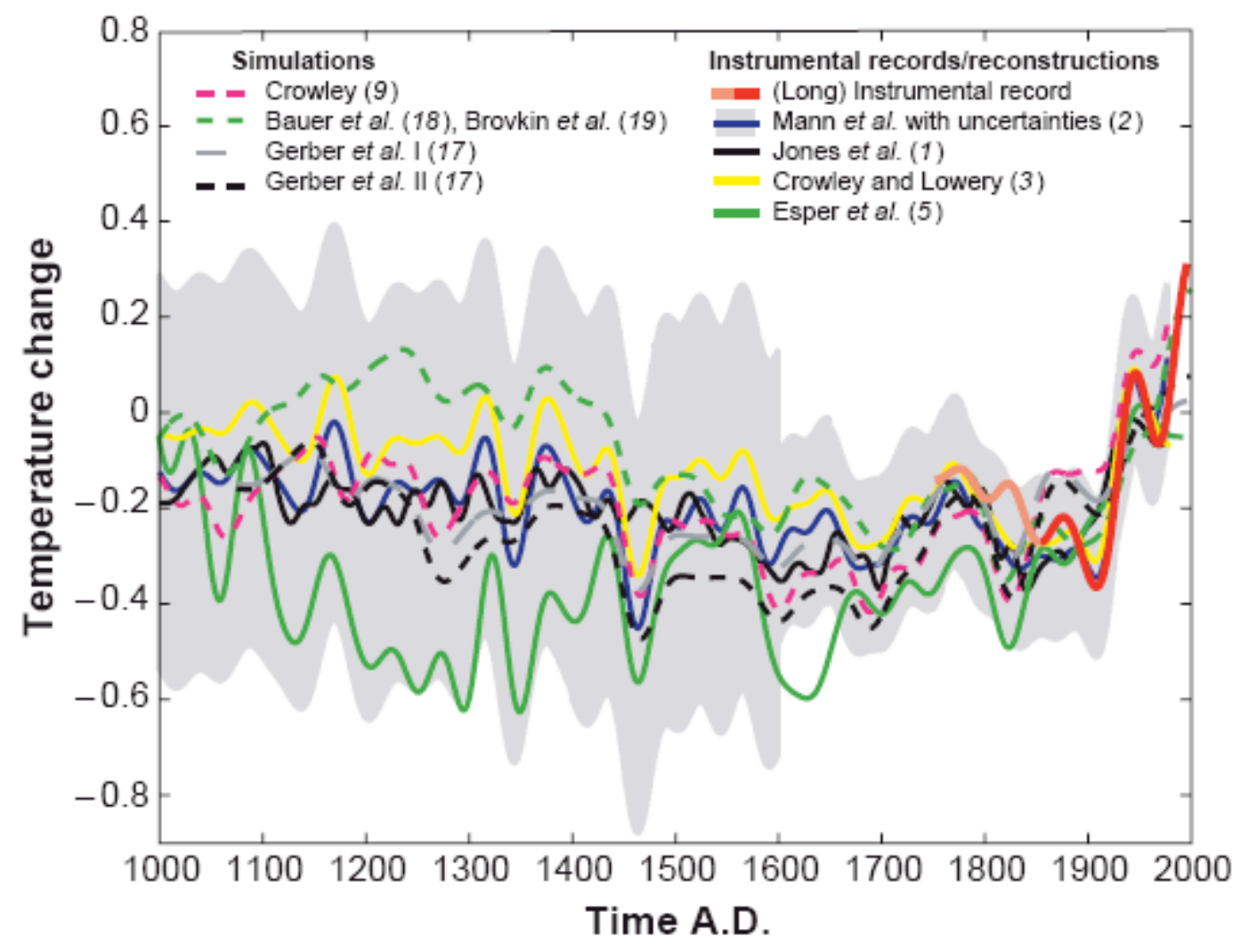

Figure 1. Northern Hemisphere temperature histories based on multiple proxies (figure taken from Mann 2002; p. 1481). 
These proxy data show that temperatures in the Northern Hemisphere over the past millennium remained fairly consistent until the past century, when temperatures warmed (Mann et al. 2002). Marine conditions in offshore Alaska have been shown to be much warmer than they are today through the use of marine sediments (BrighamGrette and Hopkins 1995). Proxy data was used to determine that the climate off Alaska in the Last Interglacial period $(\sim 125,000$ years ago) was warmer than it is today. Sea level was $\sim 6$ meters higher than present day. Summer temperatures in interior Alaska were approximately $3-4^{\circ} \mathrm{C}$ warmer, and coastal temperatures of Alaska were $\sim 2^{\circ} \mathrm{C}$ warmer than they are today (USGS 2004). Southern species such as mollusks from the North Pacific Ocean shifted northward into the Bering Strait region (Brigham-Grette 2001). In the Bering Strait region, winter sea-ice limits were $800 \mathrm{~km}$ north of the current sea-ice limits, and ice-free conditions may have been present in the Arctic Ocean during the summer (Brigham-Grette and Hopkins 1995). Current observations of warming temperatures and the reduction of sea ice (IPCC 2001; Rothrock et al. 1999) may indicate that the climate and biota could shift to conditions coincident with the Last Interglacial period (Brigham-Grette 2001). In the next section, current evidence of recent climate change in the Arctic will be presented.

\section{Current Evidence of Climate Change in the Arctic}

The Bering and Chukchi Seas undergo natural shifts in climate and are influenced by two major climate patterns, which are the Pacific Decadal Oscillation (PDO) and the Arctic Oscillation (AO). The PDO influences sea surface temperatures, and the AO primarily influences wind strength (Stabeno and Overland 
2001). Shifts in the positive or negative states of these oscillations occur every few decades and are responsible for shifts in marine biota in the area, which are called regime shifts (Hare and Mantua 2000; Steele 1996). An example of these shifts in marine biota is shown in Figure 2, when trends in catch data for sockeye salmon were compared over the years 1925-1992. In this figure, western Alaska sockeye salmon show a large jump in productivity in 1979 in response to a change in the North Pacific climate.

Western Alaska Sockeye Salmon Response to the 1979 Regime Shift

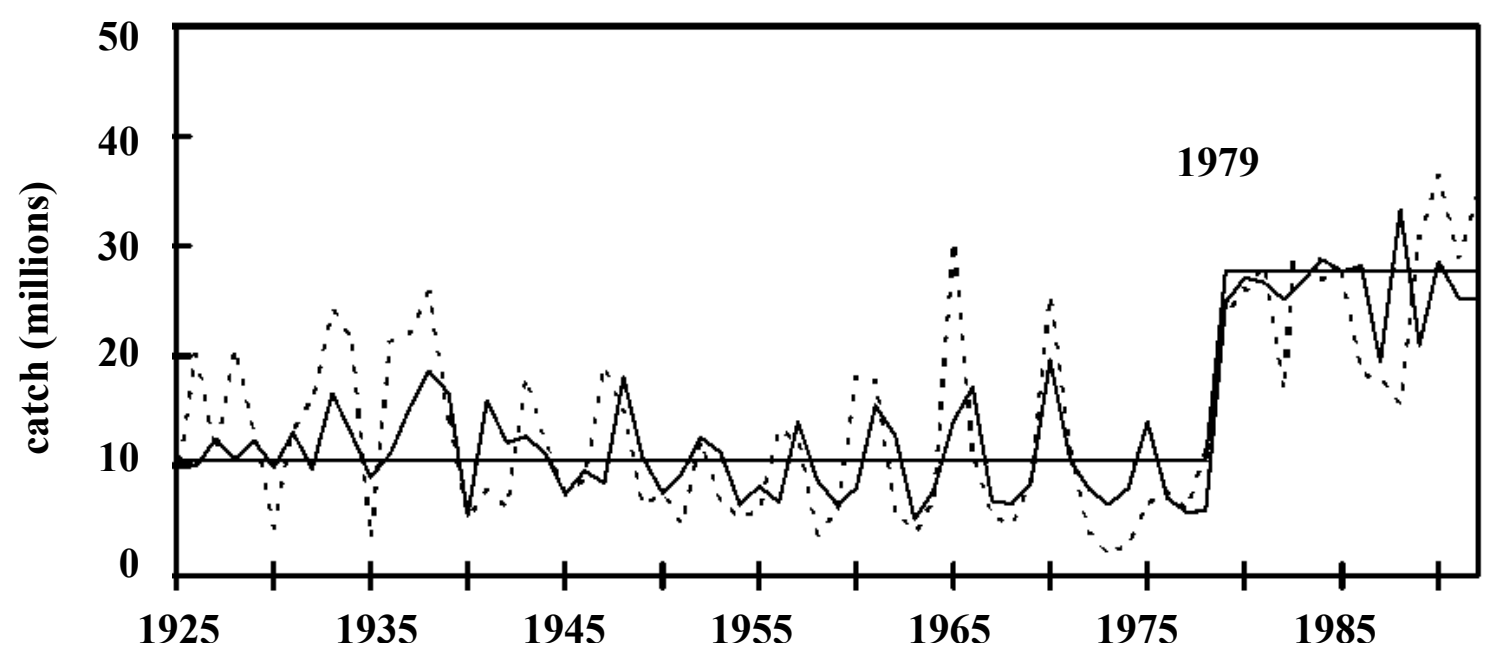

Figure 2. Plots of Alaska sockeye salmon catch when entered into a model (solid line). Landings data is indicated by dashed lines (figure taken from Hare and Francis 1995; p. 29).

Three regime shifts have been documented in the North Pacific in the last thirty years. The first regime shift occurred in the winter of 1976-1977, resulting in a pronounced warming in the Bering Sea. The second regime shift occurred in the winter of 1988-1989, resulting in a slight cooling in the same area (Hare and Mantua 
2000). The third shift has been observed in 1997-1998 (Stabeno et al. 2001). Since the 1990's, temperatures both throughout the water column and in the atmosphere have increased in the Bering and Chukchi Seas, especially during the summer months (Stabeno and Overland 2001). The increase in ocean temperatures is not only seen in the Bering and Chukchi Seas. It has been seen in every ocean in this world, which is illustrated in Figure 3 for the North Pacific Ocean (below).

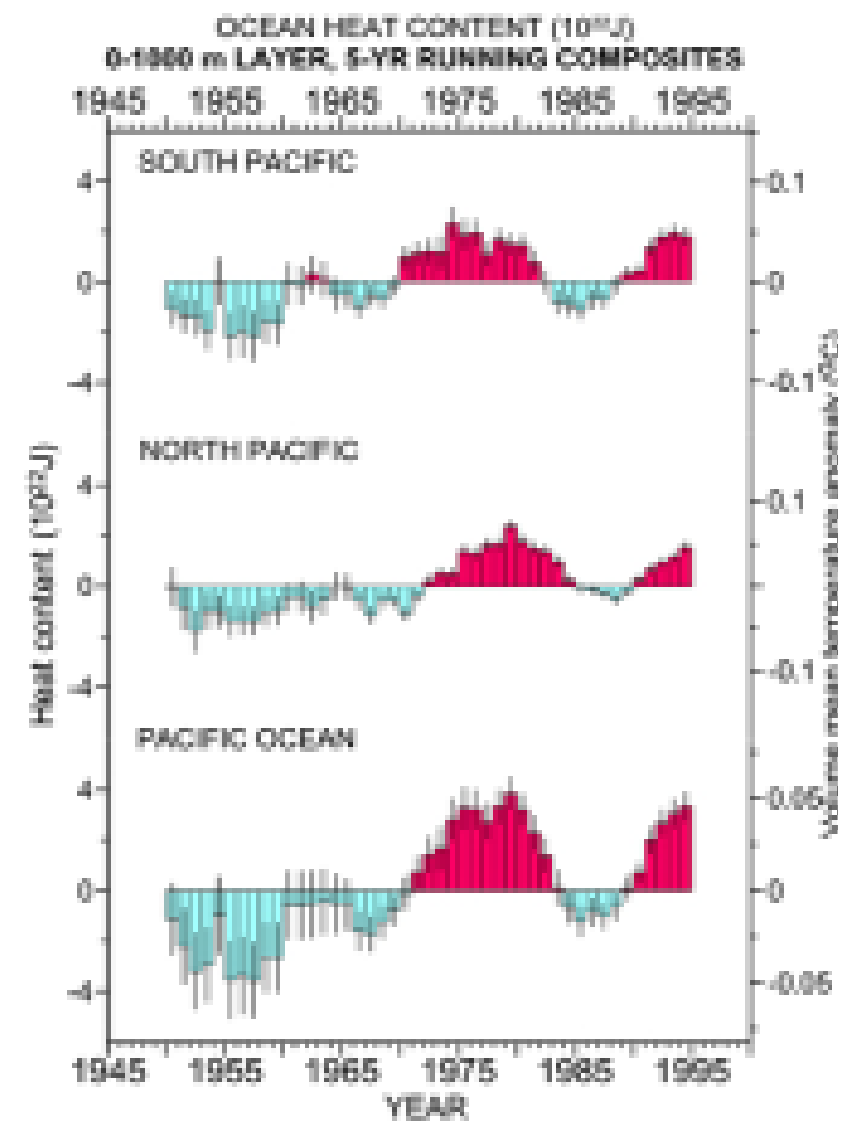

Figure 3. Warming ocean temperatures in the Pacific Ocean, 1945-2000 time series (figure taken from Levitus et al. 2000). 
This increase in temperatures could be due to natural changes in oscillation patterns, a sudden step-wise shift, or a long-term monotonous trend in temperatures. The increase in temperatures could be due to natural causes or from anthropogenically induced global warming supposedly resulting from a build-up of greenhouse gases in the atmosphere (BESIS 1997; IPCC 2001). In the past 150 years, atmospheric concentrations of greenhouse gases such as methane and carbon dioxide have increased by $151 \%$ and $32 \%$, respectively (IPCC 2001; Mantua and Mote 2002). In the past 100 years, the average global temperature has increased by $0.4-0.8^{\circ} \mathrm{C}(0.7-$ $\left.1.5^{\circ} \mathrm{F}\right)(\mathrm{IPCC} 2001)$.

Predictions for the next 100 years indicate a further temperature increase of $1.4-5.8^{\circ} \mathrm{C}\left(2.5-10.4^{\circ} \mathrm{F}\right)$ (IPCC 2001). The projected warming is expected to be amplified in the Arctic, where various models predict a temperature increase up to $10^{\circ}$ C over the next 70 years (Dixon et al. 2003). The following figure (Fig. 4) shows the dramatic and abrupt increases of global temperatures expected throughout the world, which are based on conservative estimates by models. 
Predicted Annual Mean Surface Air Temperature Increases for the Years 2065-2089

(a)

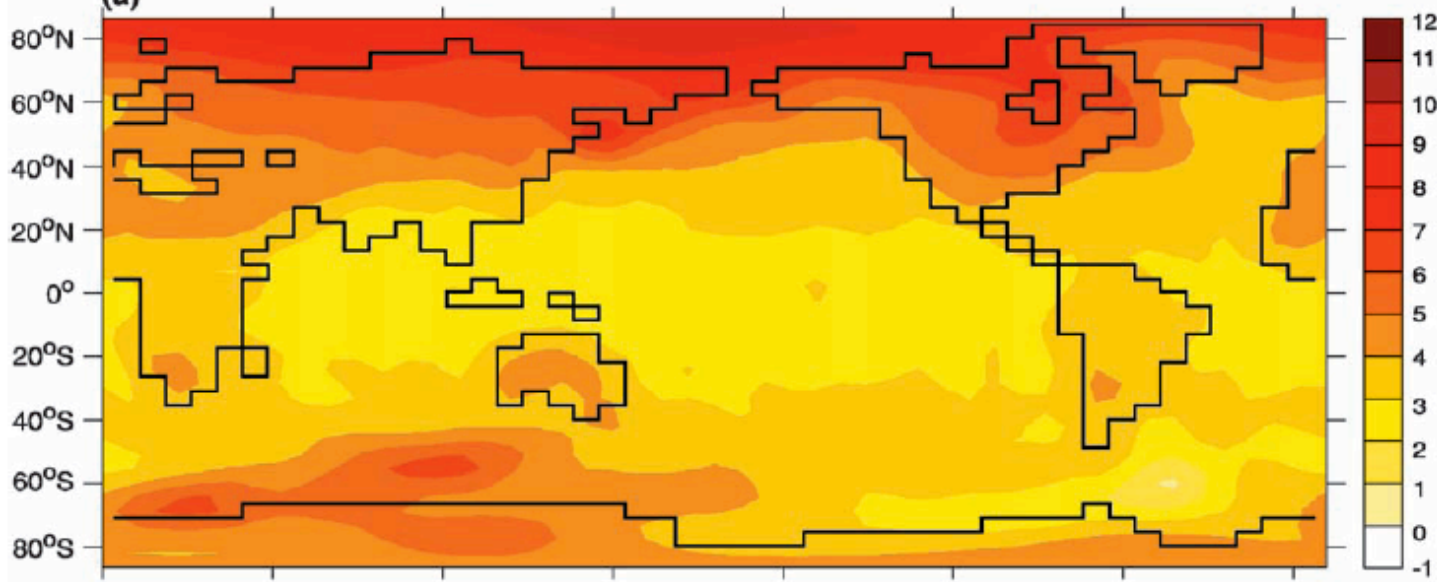

(b)
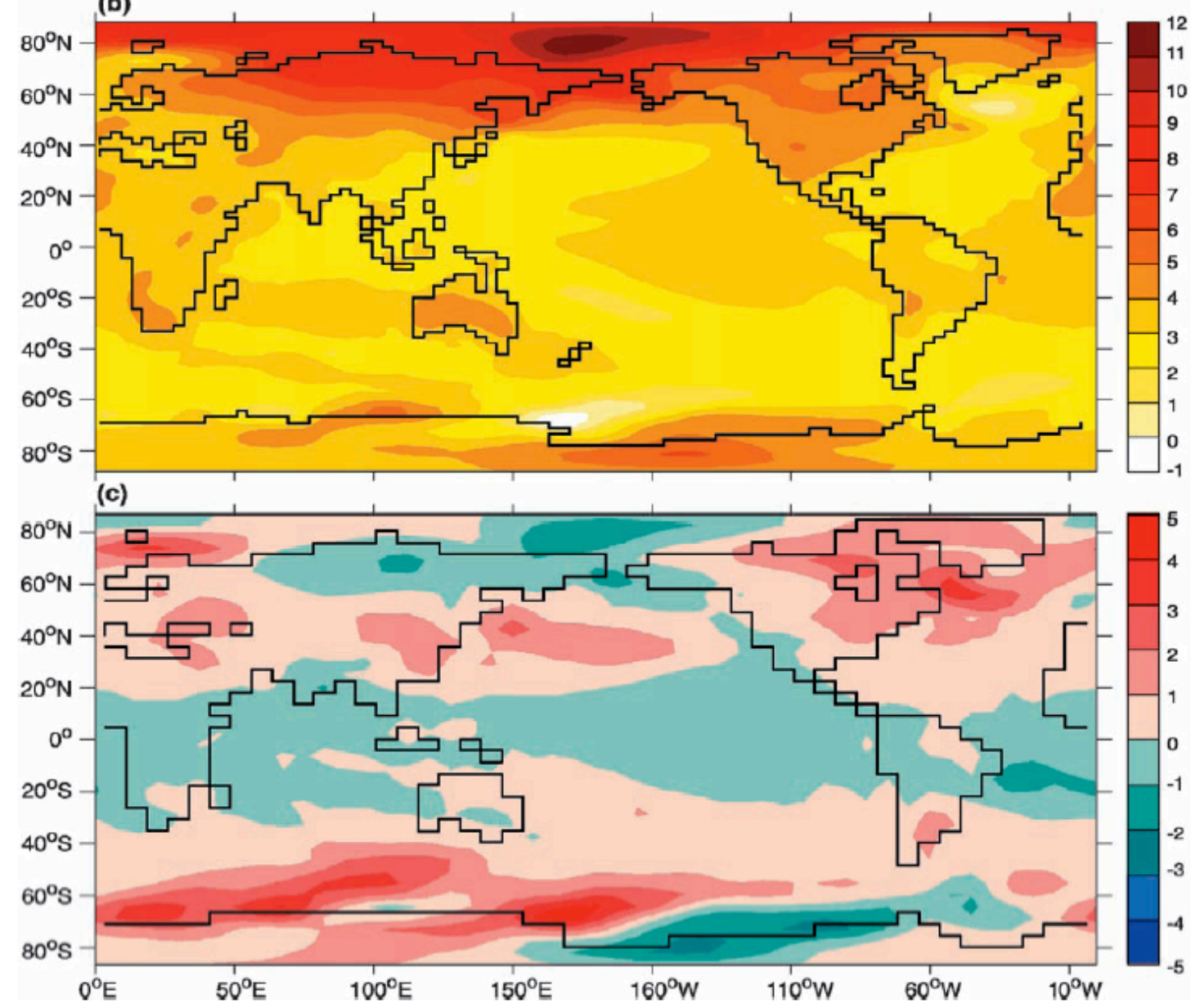

Figure 4. The predicted annual surface air temperature increases for the years 2065-2089. These predictions are based on two numerical modeling experiments depicted in (a) and (b), above. The difference between those two models is shown in (c) (figure taken from Dixon et al. 2003; p. 90). The 
difference between these two models is relatively small, from $-1{ }^{\circ} \mathrm{C}$ to $+1^{\circ} \mathrm{C}$, in the Alaskan Seas and elsewhere in the Arctic (except for the Barents Sea); therefore the projected temperature increase of about $10^{\circ} \mathrm{C}$ appears as a robust feature of the future Arctic climate.

Temperatures are expected to rise significantly throughout the polar and temperate regions. Over Alaska and the Chukchi Sea, the projected temperature increase is approximately $10^{\circ} \mathrm{C}$ (Dixon et al. 2003). Whether the cause of warmer temperatures is natural or human-induced, the fact is that temperatures are warming at an accelerated pace around the globe (Comiso 2003; Jones et al. 1999). In the Arctic, physical oceanographers are seeing air and water temperatures that are the warmest on record. Water temperatures have increased substantially throughout the water column in the entire region (Phyllis Stabeno, pers. comm. 2004). Long-term temperature data for the Arctic reveal that the increase in surface temperatures over the past 20 years is eight times larger than the 100-year trend in temperatures (Comiso 2003). This accelerated warming has resulted in changes in ecosystems and species within the Bering and Chukchi Sea ecosystems (Krupnik and Jolly 2002; Stabeno and Overland 2001). One of the consequences of warming ocean temperatures is a decrease in the extent and thickness of sea ice (Comiso 2002). The following section reviews the current status of sea ice in the North Pacific Ocean relative to climate change.

\section{Diminishing Sea Ice due to Climate Change}

The Arctic is currently undergoing a large decrease in sea ice cover due to warming temperatures (Bjorgo et al. 1997). Since the 1980's the first-year sea ice 
cover $^{6}$ has been reduced by approximately 3 percent per decade (Rothrock et al. 1999), while the multi-year ice ${ }^{7}$ cover has been reduced by approximately 9 percent per decade (Comiso 2002). The biggest decrease in multi-year sea ice extent has been in the Beaufort and Chukchi Seas, which correlates with the anomalously warm temperatures in these regions over the past few years (Comiso 2002). In these seas, new records for the minimum sea ice extent ${ }^{8}$ have been established repeatedly since 1980. Since 1980 , the minimum sea ice extent has been $25 \%$ below the lowest values recorded over a forty-five year period (Maslanik et al. 1999). In the Bering Sea, sea ice extent has decreased by 5 percent over the past forty years, with the most notable decrease occurring since the 1970s (BESIS 1997). Areas of open water throughout the Arctic have become much more frequent in recent years, especially during the summer months (Comiso 2002). The loss of sea ice in the Bering and Chukchi Seas is illustrated in the following figure (Fig. 5).

\footnotetext{
${ }^{6}$ First-year sea ice is defined as sea ice that forms during the onset of winter each year. First-year sea ice is typically the ice that forms in the southern regions of the Bering and Chukchi Seas during the winter months (Comiso 2002, 2003; Rothrock et al. 1999).

${ }^{7}$ Multi-year ice is several years old and typically resides in the northern Arctic regions of the Chukchi Sea and Arctic Ocean (Comiso 2002, 2003).

${ }^{8}$ Minimum sea ice extent is defined as the smallest area of sea ice remaining after the summer melt period, prior to the onset of the winter sea ice formation season. Maximum sea ice extent is defined as the largest area of sea ice that is formed during the winter months, prior to the onset of the spring melt season (Comiso 2002).
} 


\section{Winter Percent Ice Cover for the Bering and Chukchi Seas}

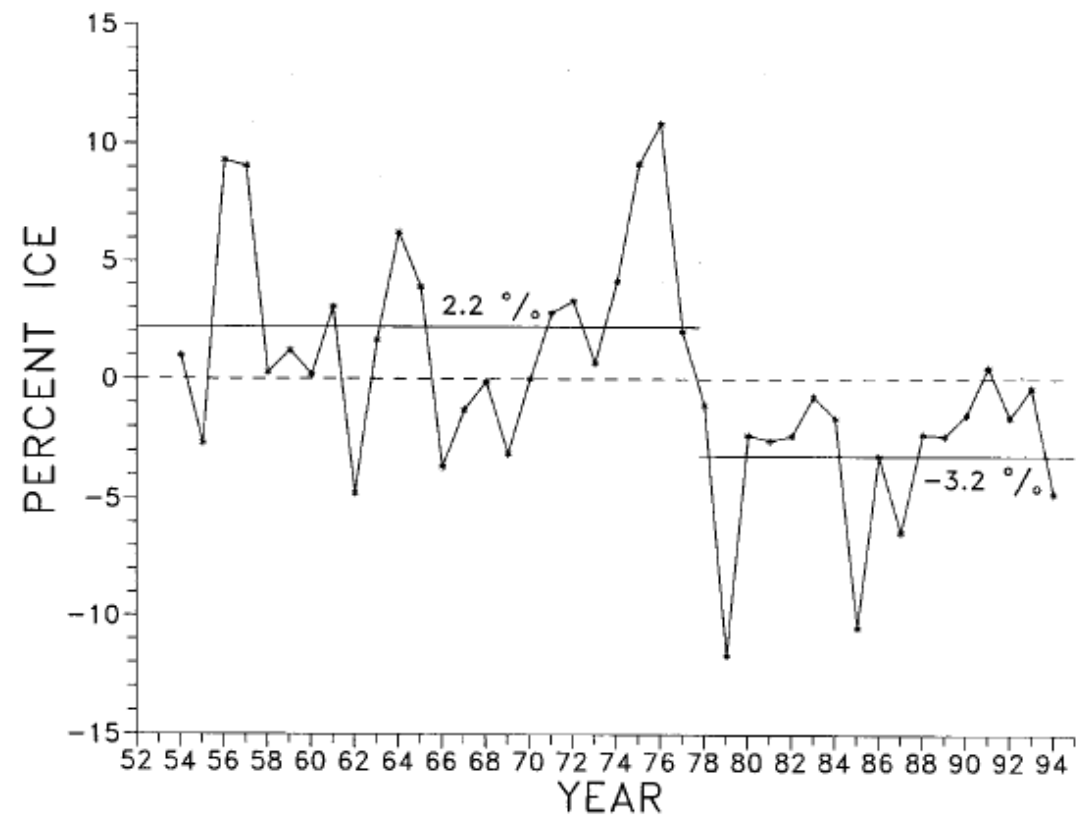

Figure 5. Winter average percent ice cover anomalies for the Bering and Chukchi Seas, 1952-1995 (figure taken from Niebauer et al. 1999; p. 52).

Sea ice cover has not been the only characteristic to change. Sea ice thickness has also decreased, which also indicates warming temperatures. Since the 1960 s, sea ice thickness in the central deep water Arctic Ocean has decreased as much as 40 percent, from 3.1 meters to 1.8 meters (Rothrock et al. 1999). Although decreases in sea ice thickness have been greatest in the central and eastern Arctic (Rothrock et al. 1999), sea ice at Barrow, Alaska in 1998 was thinner than ever observed. During this time, sea ice thickness decreased from an average of 1.7-1.8 meters to 1.4 meters (Weller 2000).

The observed sea ice variability might have resulted from natural causes. However, studies done by Vinnikov et al. (1999) have shown that "the probability of the witnessed reductions in sea ice cover being caused by natural climate variability is 
less than 0.1 percent for the observed 1953-1998 sea ice trends [and less than 2 percent for the 1978-1998 trends]. This evidence strongly suggests that the observed decrease in northern hemisphere sea ice extent is related to anthropogenic global warming (Weller 2000; p. 53).”

If trends of sea ice thinning and retreat continue at the current rate, the biotas of this region are likely to change (Comiso 2002; IPCC 2001). This is important because commercial fish is the primary biota of the Bering Sea region (NRC 1996). Fish are highly sensitive to ocean temperature changes (Crawshaw and O'Connor 1996; Laevastu 1993), so any warming of ocean temperatures combined with the retreat of sea ice could result in a northward shift in the distribution of commercially viable fish species (IPCC 1997, 2001). Distributional shifts of commercial fish species have already occurred to a limited degree in both the Atlantic and Pacific Oceans (Benson and Trites 2002; Oiestad 1994). The next section of this chapter will discuss the behavioral response of fish to warming ocean temperatures in the Atlantic Ocean.

Evidence for Fishery Shifts in the Atlantic Ocean due to Warming Temperatures

Fish species are highly sensitive to water temperatures. Studies indicate that as lower latitude temperatures warm, fish native to a specific geographical area will exhibit three response mechanisms. They will adjust their body temperatures by thermoregulation, vary their depth within the water column, or remain at their depth but shift their latitude (Crawshaw and O’Connor 1996; Laevastu 1993). 
In the Atlantic, large-scale shifts have occurred in the distributions of fish species in response to warming ocean temperatures. During the Little Ice Age, thinning sea ice coincided with an increase in Northeast Arctic cod (Oiestad 1994). In a different region between the years 1920-1960, the West Greenland cod stock moved towards the Arctic in response to warmer atmospheric temperatures (Brander 1997). Prior to 1917, very few cod were present offshore of West Greenland, however, a prolonged warm period in the Northern Hemisphere resulted in the poleward extension and increase in abundance of cod and many other boreal species. The large abundance of cod prompted the Greenland Administration to establish a succession of fishing stations along the coast to process the fish. When temperatures cooled in the 1960's, the stocks retreated back into southern waters (Brander 1997).

During the same period (1920-1960), the Norwegian Spring Spawning Herring migrated to Iceland to feed, but after the ocean temperatures decreased by one degree Celsius, the herring gradually disappeared from Iceland (Loeng 2001). A period of very mild winters in the North Sea from 1988-1990 coincided with a northward shift of the herring feeding grounds. This could have been due to the northward shift in distribution of the sand lance, which is their main source of prey (Corten 2001). In addition, cold-water migratory species have the greatest interannual variation in latitude. Atlantic herring and mackerel will respond to a $1^{\circ} \mathrm{C}$ temperature increase by shifting their distributions poleward by $110 \mathrm{~km}$ (Crawshaw and O'Connor 1996).

In the Pacific Ocean, warming temperatures have a similar affect on fish distributions. The next section will discuss the behavioral response of fish to warming ocean temperatures in the Pacific. 
Evidence for Fishery Shifts in the Pacific Ocean due to Warming Temperatures

Pollock are extremely sensitive to changing temperatures, as exhibited by their distributional shifts related to the fluctuating cold $\left(<2^{\circ} \mathrm{C}\right)$ water pool in the Bering Sea (Schumacher et al. 2003). The cold pool extends $\sim 200 \mathrm{~km}$ north $/$ south and $\sim 500 \mathrm{~km}$ east/west and is believed to inhibit demersal fish migration to northern areas of the Bering and Chukchi Seas. For example, the distribution of pollock is greatly affected by variations in sea ice cover and the location of the cold pool (Wyllie-Echeverria 1995; Wyllie-Echeverria and Wooster 1998; Benson and Trites 2002). Pollock typically inhabit areas of water $>2^{\circ} \mathrm{C}$, and during years of reduced sea cover pollock expand their distributions north farther onto the shelf (Buckley et al. 2001; WyllieEcheverria 1995; Wyllie-Echeverria and Wooster 1998).

Strickland and Sibley (1984) predicted that under a global warming scenario, both the habitat and range of pollock could expand northward, allowing pollock to colonize areas such as the Chukchi and Beaufort Seas. This habitat expansion would be due to reduced ice cover, reduced water stratification, and warmer ocean temperatures, all of which combine to result in more spawning area and an increase in the pollock food supply (Strickland and Sibley 1984).

In the colder years prior to the regime shift of 1977, pollock were not found above the Bering Strait. In years of light ice cover since 1977, pollock have been found above the Bering Strait in the Chukchi Sea (Wyllie-Echeverria 1995; WyllieEcheverria and Wooster 1998; Benson and Trites 2002). Larval pollock have also been found in the Chukchi Sea, which suggests a change in the spawning distribution of some of the population (Wyllie-Echeverria and Wooster 1998). 
Adult walleye pollock (age $2+$ ) have changed their distributions on the shelf since 1975 (Hunt et al. 2002). In 1975, 65\% of pollock were found on the south outer and south middle shelves. By the late 1990 's, $81 \%$ of the pollock biomass shifted north onto the north outer and north middle shelves, where only $31 \%$ of the pollock biomass had been in 1975. The declines seen in pollock biomass in the survey areas since 1996 "may indicate that pollock have shifted their distribution northward, outside of the survey area (Hunt et al. 2002, p. 5835).”

During years of warmer bottom water and a diminished cold pool, the distributions of Greenland turbot, yellow Irish lord, and thorny sculpin are more widespread on the shelf than in colder years (Wyllie-Echeverria and Wooster 1998). Pacific cod and arrowtooth flounder prefer colder habitats, so during years of heavy ice cover and a larger cold pool these species will distribute north over a wider area of the shelf. Arctic cod will shift their distributions farther south into the Bering Sea during colder years as well (Wyllie-Echeverria and Wooster 1998).

In recent years the amount of jellyfish in the Bering Sea has increased substantially. Jellyfish were primarily limited by sea ice extent, but warming temperatures have resulted in a reduction in sea ice extent, thus allowing jellyfish to expand their distribution over the eastern shelf in recent years (Brodeur et al. 1999).

Salmon are also highly influenced by ocean temperatures. Sockeye and pink salmon have been captured near Banks Island, Canada, which is well outside their normal Pacific range (Babaluk et al. 2000). Another report shows a positive correlation between decreases in sea ice extent and salmon that have returned to the area (based on catch data; Quinn et al. 1989). In addition, spawning locations may 
change as water temperatures warm. In the Arctic, new streams have been occupied by spawning populations of salmon. These streams had not previously been used for spawning because water temperatures and ice cover were too extreme for salmon to populate these streams (Charles Lean, pers. comm. 2004).

In 1997 during the onset of an El Nino that brought higher than normal temperatures into the Bering Sea region, unprecedented sightings of southern fish and marine mammal species occurred in the North Pacific and Bering Sea, such as yellowfin tuna, sunfish, and Pacific white-sided dolphins (Kruse 1998). Albacore tuna shifted their distributions north in 1997 and a high seas albacore tuna fishery developed approximately 1,200 miles from Kodiak, Alaska. The albacore tuna fleet size increased from 35 to 200 vessels in one season (CRS 1997). Northern anchovies shifted north as evidenced by analyses of the salmon stomachs in Yakutat, which is located northwest of Juneau at $59.5^{\circ} \mathrm{N}$ latitude and $140^{\circ} \mathrm{W}$ longitude. In addition, the offshore walleye pollock fishing fleet shifted their operations north of their normal fishing grounds (Kruse 1998).

\section{Concluding Remarks}

The evidence presented in this chapter shows that the Bering and Chukchi Sea ecosystems are changing due to the warming of both ocean and atmospheric temperatures. The current fisheries management regime does not take these changes into account, and management action may be needed in the future if commercial fisheries shift into new areas such as the Chukchi Sea. Considering the fisheries management system in place is primarily a reactive system that addresses issues after 
they arise (Dayton 1998; Pew Report 2002), it may be a desirable goal to do the opposite in the climate change scenario discussed above. In this climate change scenario, fishery managers could anticipate a potential situation and manage proactively by planning for distributional changes in their fish stocks (Magnuson 2002; Parsons 1991; Rosentrater and Ogden 2003). Proactive management via planning and the use of the precautionary approach would allow fishery managers to thwart overfishing or negative impacts on the ecosystem prior to their onset (Young 1998).

In the next chapter, the human environment of the Chukchi Sea region will be discussed. Evidence of climate change will be presented through the observations of Native peoples, and will be followed up with a discussion on how these peoples could be affected by the development of new commercial fisheries in the Chukchi Sea. 


\section{Chapter 3}

\section{Alaska Natives of the Chukchi Sea}

The purpose of this chapter is to briefly review the subsistence lifestyles of Alaska Natives, the issues these peoples currently face in their society, and how these peoples could both be affected by and involved in the management of new commercial fisheries developing in the Chukchi Sea. In this thesis research, several research questions were posed to the respondents at the ARCUS and ICASS V conferences and during the formal interviews in Anchorage and Juneau, Alaska. Respondents were asked their opinions on: 1) whether or not Alaska Natives would be affected by new fisheries development in the Chukchi Sea; 2) how these peoples could be involved in the management of new resources moving into their area, and 3) who should be involved in the management of new commercial fisheries in the Chukchi Sea. This chapter will provide background material behind the rationale for asking respondents the above three questions.

\section{Background on Alaska Natives in the Chukchi Sea Region}

Alaska Natives have a long history of living in coastal communities along the Chukchi Sea, and these peoples have been living subsistence lifestyles for thousands of years (Ray 1975). Living the subsistence lifestyle is more than just living off the land; it is a whole way of life in which Natives' culture and their conceptions of themselves are tied to the land and resources (NRC 1999). Their subsistence food sources include fish, terrestrial and marine mammals, plants, fowl, and eggs. In the 
past, clothing was made from the skins of seal, walrus, caribou, ground squirrel, muskrat, and birds. Natives constructed boats from wood and the skins of walrus and seals. Winter shelters were made from wood and turf, while summer shelters were often made from the skins of walrus and other sea mammals. In 1778, Captain James Cook and his crew became the first Europeans to visit the mainland of Alaska above the Aleutian Islands (Ray 1975).

The presence of Europeans had an effect on the culture and lifestyles of these peoples; however, Alaska Natives have continued to live subsistence lifestyles and have maintained their cultural bond to marine and terrestrial resources (Laughlin 2002). Money is now an important part of maintaining these lifestyles, so Alaska Natives now work so they can afford the capital used for subsistence hunting and fishing (Callaway 1998; Lonner 1986). The resources harvested have primarily remained the same, but Alaska Natives have become entirely dependent upon modern hunting and fishing technology. Rifles have replaced traditional harpoons and bows and arrows, small planes are used to scout out game, four-wheelers and snowmobiles are used to bring the game home, and boats with motors are used to hunt marine mammals and fish (NRC 1999). The use of modern technology has not been the only change in Alaska Natives' lives. In recent years their environment has been changing rapidly in response to climate change, and the resources they harvest have been directly affected by changes in sea ice and increases in temperature (Krupnik 2000a; 2000b). 


\section{Climate Change and Alaska Natives}

Climate change is one of the most significant issues that Alaska Natives currently face in their society. Natives across the Arctic have begun to notice major changes in the landscapes and seascapes of the north (Nuttall 2001; Wohlforth 2004), which is due to the record-breaking warm temperatures over Arctic North America in recent years (Comiso 2003; IPCC 2001). Changes in weather patterns have brought storms that are not typical to northern latitudes, such as thunder and lightening. Many Arctic residents have never witnessed these storms, which have been triggered by warmer, moister air now resident in these regions (Nuttall 2001). Winds have changed direction and can no longer be relied upon for navigation. Snow cannot be relied upon for travel due to its patchiness or absence in some areas, and ice cellars can no longer keep food frozen due to the melting of permafrost (Nuttall 2001).

The species and distribution of vegetation cover have changed as temperate woody species of trees push into northern areas (Thorpe et al. 2002). This has a direct effect on the migration paths and distribution of terrestrial mammals such as caribou, because caribou tend to favor areas with lush green vegetation. Caribou migration paths are also influenced by the earlier opening of ice leads in rivers, becoming problematic because caribou prefer to migrate across ice. The result is a redistribution of caribou that influences the hunting patterns of Alaska Natives (Thorpe et al. 2002).

Southern species of birds, fish, insects, and marine mammals are now found in the Arctic due to warming temperatures and the thinning and retreat of sea ice (Babaluk et al. 2000; Fox 2002). Spring break-up of the sea ice is coming earlier, while winter freeze-up is coming later (Nuttall 2001). The sea ice is less predictable 
and it is difficult for sea mammal hunters to hunt effectively. Hunters may decide to hunt closer to shore due to fears that the ice will break away and they will drift out to sea (Wohlforth 2004). Many hunting groups have been stranded on sea ice that has broken away from the shore (Norton 2002; Wohlforth 2004), thus requiring the use of helicopters to rescue them (Wohlforth 2004). Natives across the Arctic have noticed the changes in sea ice, such as in Barrow and Elim, Alaska, where two individuals observed:

We are seeing many differences in the quality of sea ice. It is less salty, easier to chop, and [it] breaks up sooner. The fast ice retreats early. It breaks up and retreats 20-30 miles and doesn't come back. We used to have ice come in fall time, but now the water freezes up in place and we don't see the ice floes drifting to shore. Multi-year ice doesn't arrive till later.

- Charles D.N. Brower, Barrow, Alaska. (Krupnik 2000b; p.40)

We can see changes in our environment- I am from the northeastern Bering Sea- southern Seward Peninsula area...the ice is not stable anymore, it is not too good in springtime. I don't know, maybe the water temperature is coming up...the shore ice is melting so fast- it's like opening your hot water socket, and the ice is melted away at once...I don't know what's going on with our weather and what is going to happen. Because these changes may affect our ways of subsistence hunting, and also the fish stocks. It may impact the whole system.

-Charles Saccheus, Elim, Alaska. (Krupnik 2000b; p.38)

The decline in the extent and thickness of sea ice has affected Alaska Natives to such a degree that Inuit hunters represented by the Inuit Circumpolar Conference have brought a claim to the United Nations stating that the thawing of this ice has threatened Inuit human rights (Doyle 2004). They claim that the hunters have to be 
out on the ice, and when hunters fall through the thinning ice their rights are being violated because countries such as the United States have not done anything to curb global warming. This appeal to the UN is primarily an attempt to put pressure on the United States and other developed nations to ratify the Kyoto Protocol ${ }^{9}$ (Doyle 2004). Alaska Natives' subsistence lifestyles could be affected if they cannot harvest their traditional species due to changes in distribution and/or abundance (Krupnik and Jolly 2002). If the sea ice continues to retreat north, many ice-dependent or iceassociated marine mammals may move into northern regions, thus becoming inaccessible to Native hunters to the South (Stirling 1997; Stirling et al. 1999; Tynan and DeMaster 1997). To minimize the negative impacts of climate change on these subsistence lifestyles, Alaska natives could adapt by taking alternative marine and terrestrial species, while taking advantage of new opportunities that could arise such as commercial fisheries (Whitney et al. 2000).

\section{Climate Change, Alaska Natives, and New Commercial Fisheries Development}

Past industrial development in the Arctic has had a positive effect on communities through the development of new employment opportunities; however, industrial development has had negative effects on the environment and on social conditions within Arctic communities (Haley 2004). New commercial fisheries development could have the potential to negatively affect the environment through the spread of invasive species, pollution, interactions with freely swimming marine mammals, and through disruption of the Chukchi Sea ecosystem. This would have a

\footnotetext{
${ }^{9}$ The Kyoto Protocol is a document that intends to decrease global warming through reductions in the allowable amount of greenhouse gases a country puts into the atmosphere.
} 
direct negative effect on marine resources Alaska Natives harvest for their subsistence lifestyles. Natives' culture revolves around the resources harvested from the land and sea, so any negative effects of commercial fisheries development on the environment would have the potential to negatively affect the culture of these Native peoples (Rosentrater and Ogden 2003). However, these peoples could be positively affected by being involved in new commercial fisheries development, both economically and through self-determination (by being involved in the management aspects of new commercial fisheries development) (Nuttall 2001). Both forms of involvement have the potential to positively affect Alaska Natives. In this thesis research, it is important to distinguish between involving Alaska Natives in management decisions of developing commercial fisheries, and involving Alaska Natives through the allocation of economic opportunity.

Native peoples maintain a strong cultural bond with resources from the land and sea, which remains an integral part of the culture of these peoples. Therefore it may become important for those affected by commercial fisheries development to be involved in management decisions regarding fishery resources moving into the Chukchi Sea. Even though fish stocks moving into their region will not be those "traditionally" harvested by these peoples, commercial development could have an indirect negative effect on marine mammals and other resources Alaska Natives depend upon. Therefore Alaska Natives may want to be involved in management decisions because those decisions have the potential to harm their traditional way of life. By being involved in the management of new fish stocks moving into the Chukchi Sea, Alaska Natives may be able to influence where, when, and how fishing 
can be done, thus minimizing the negative effects of new commercial fisheries development on both the environment and their culture. The direct involvement of Alaska Natives in new commercial fisheries management could be done through a comanagement agreement. Co-management is a power-sharing agreement between the government and local communities that allows local communities to make management decisions (Pinkerton 1989).

On the other hand, Alaska Natives in the Chukchi Sea region may want to be involved in the economic benefits of fisheries development. New economic opportunities could provide revenue and new jobs to the Chukchi Sea region, thus supporting their subsistence lifestyles that have already been affected by climate change. If these peoples wanted to be involved in new commercial fishing opportunities, they would have to acquire the necessary capital to take part in these capital intensive new fisheries. New commercial fisheries in the Chukchi Sea would be capital-intensive because new boats, gear, bait, fuel, and other supplies would have to be acquired, and processing plants would have to be built. Alaska Natives could be involved in the economic aspects of new commercial fisheries development through the use of the Western Alaska Community Development Quota (CDQ) program (MSFCMA, P.L. 94-265, § 305 (i) (1)).

The CDQ program provides communities with a share of the CDQ total allowable catch and helps them acquire the capital to carry out commercial fishing (NRC 1999). The CDQ program was originally developed under the Bering Sea/Aleutian Islands Groundfish (BSAI) FMP, and then later the CDQ program was enshrined in the Magnuson Stevens Fishery Conservation and Management Act 
(MSFCMA). The MSFCMA states that communities eligible for the CDQ program must be located within 50 nautical miles from the baseline of the Bering Sea (MSFCMA, P.L. 94-265, § 305 (i) (1) (B)). Therefore communities residing along the Chukchi Sea could not be included in this program unless the MSFCMA was amended to include eligible communities in both the Bering and Chukchi Seas.

New commercial fisheries development has the potential to both positively or negatively effect communities residing along the Chukchi Sea. Positive effects include the creation of new employment opportunities (through Natives' involvement in the CDQ program) and by self-determination (by being involved in management opportunities). Negative effects include harms to the environment and marine resources, thus negatively affecting the culture of Alaska Natives living subsistence lifestyles. However, by being involved in making management decisions, Alaska Natives may be able to minimize the negative effects of commercial fishing on their environment, resources, and their culture. ${ }^{10}$

This chapter has explained how Alaska Natives could be both affected by and involved in new commercial fisheries development in the Chukchi Sea. In this thesis research, it was evident that Alaska Native communities within 50 miles of the Chukchi Sea could be involved in the allocation of economic opportunity by amending the MSFCMA and creating a new CDQ group specific to the Chukchi Sea. The question that was posed to the respondents was not how to involve Alaska Natives in the economic benefits of new commercial fisheries development, but how to involve them in management decisions made concerning the development of a region that has

\footnotetext{
${ }^{10}$ By being involved in management and by minimizing the negative effects of commercial fishing on their environment and resources, Alaska Natives may be able to minimize the negative effects on their culture because they can keep watch over their traditional resources.
} 
yet to be affected by large-scale commercial fishery harvests. The results of these research questions will be presented in Chapter 5 .

The next chapter will review the current fisheries management regime in place for the Bering and Chukchi Seas. A review of fisheries management on the federal, state, and international levels will be discussed with the purpose of elaborating why a new fisheries management regime is needed for any fisheries moving into the Chukchi Sea region. 


\section{Chapter 4}

Institutional Structure of Fisheries Management in the Bering and Chukchi Seas

There is currently an institutional vacuum with regards to fisheries management in the Chukchi Sea. There are no federal fishery management plans for any species north of the Bering Strait, nor any international agreements that regulate fisheries in the Chukchi Sea. The State of Alaska currently manages commercial ${ }^{11}$ and subsistence fisheries in state waters of the Chukchi Sea. Any development of new fisheries in federal waters of the Chukchi Sea would require new federal fisheries management in that region, and possibly an international agreement that ensures Russia does not undercut the efforts of U.S. fishery management.

Fisheries management in the Chukchi Sea could be done proactively by developing a plan for species that move into the Chukchi Sea, thus thwarting any overfishing prior to its inception. Alternatively, any new fisheries developed in the Chukchi Sea could be managed reactively, as they are in the Bering Sea. Fisheries management in the past has been reactive in nature. In reactive fisheries management, a fishery develops, the fish stock is exploited, and management responds by putting a management plan in place (often this last step occurs only once the stock in question has been overexploited). A proactive approach seeks to reverse potential overfishing by putting a plan in place prior to or immediately following the inception of fishing (CCAMLR 2004; Parkes 2000). A proactive plan for the Chukchi Sea would be

\footnotetext{
${ }^{11}$ Commercial fisheries managed in state waters of the Chukchi Sea include salmon and herring.
} 
particularly appropriate because the environment is likely to be in a state of flux, so any fishing could be damaging to this untouched sea.

In this thesis research, five of the seven research questions pertain specifically to future fisheries management in the Chukchi Sea region. The respondents were asked their opinions on: 1) what future fisheries management should look like in the Chukchi Sea; 2) whether this management should be proactively developed and put in place prior to fishery development; 3) whether Alaska Natives would be affected by new fisheries development in the Chukchi Sea; 4) how these peoples could be involved in the management of new resources moving into their area; and 5) who should be involved in the management of new commercial fisheries in the Chukchi Sea.

As noted, fisheries management in the Bering Sea is done reactively, so if fisheries were to develop in the Chukchi Sea there is a possibility that management would mirror that approach. Therefore, this chapter will focus on what fisheries management might look like in the Chukchi Sea if management mirrors that done in the Bering Sea. Chapter 6 will take this discussion further and elaborate on why future fisheries management in the Chukchi Sea should not just be an extension of current management. In the next section, the current management of commercial and subsistence fisheries by federal, state, and international fishery management authorities in the Bering Sea will be discussed. 
Federal Fisheries Management in the Bering Sea

Federal Management of Commercial Fisheries in the Bering Sea

The Fishery Conservation and Management Act (FCMA) ${ }^{12}$ was passed in 1976, which claimed jurisdiction over fish stocks residing out to 200 miles from the U.S. baseline (MSFCMA, P.L. 94-265, § 101 (a)). This 200-mile zone was divided into state waters (0-3 miles), and federal waters (3-200 miles). The 3-200 mile zone was initially called the Fishery Conservation Zone (FCZ). The FCZ was superseded by the Exclusive Economic Zone (EEZ) in 1983 when President Reagan proclaimed the U.S. EEZ via a Presidential Proclamation. By claiming out to 200-miles, the U.S. was able to phase out foreign fishing over time. The domestic fishing fleet then went through a period of expansion and development which was aided by loan guarantees for vessels and capital construction funds provided by the U.S. government (Young 1982; USCOP 2004). The rapidly expanding domestic fishing fleet began harvesting fishery resources at a rapid pace, just as the foreign fleets had done in the past (Young 1982).

To control this unsustainable harvest, the MSFCMA mandated that eight regional fishery management councils be developed to regulate fishermen. These councils, whose membership is composed of state and federal resource managers, user groups (fishermen), tribal members, and the public, represent a decentralized democratic approach towards fisheries management. These councils develop Fishery Management Plans (FMP's), which cover all fish species needing management within the councils' jurisdiction (MSFCMA, P.L. 94-265, § 302 (a)(G)). The councils must

\footnotetext{
${ }^{12}$ The FCMA was amended several times and is now called the Magnuson Stevens Fishery Conservation and Management Act (MSFCMA).
} 
ensure that the FMP's adhere to and are consistent with the 10 national standards reported in Appendix A of this thesis (reproduced from the MSFCMA, P.L. 94-265, $\S$ 206c, 301). These national standards were designed to promote conservation and management while taking into account fishing communities and the safety of life at sea (MSFCMA, P.L. 94-265, § 301 (a)).

After an FMP is developed by the council in accordance with these national standards, it is sent to the Secretary of Commerce for approval (MSFCMA, P.L. 94$265, \S 304)$. The approval process is often delegated to the National Marine Fisheries Service. Therefore, the councils develop the FMP's and are in charge of allocation, but NMFS is in charge of approving, implementing the plans, and enforcing the regulations in the EEZ (MSFCMA, P.L. 94-265, § 304).

The North Pacific Fishery Management Council (NPFMC) manages commercial, recreational, and subsistence fisheries in the EEZ off Alaska. The NPFMC has authority over all fisheries in the Arctic Ocean, Bering Sea, and Pacific Ocean seaward of Alaska (MSFCMA, P.L. 94-265, § $302(\mathrm{a})(\mathrm{G})$ ). The following figure (Fig. 4) shows the U.S. EEZ and the regions under council jurisdiction. The NPFMC has authority over fisheries in the Alaska region. 


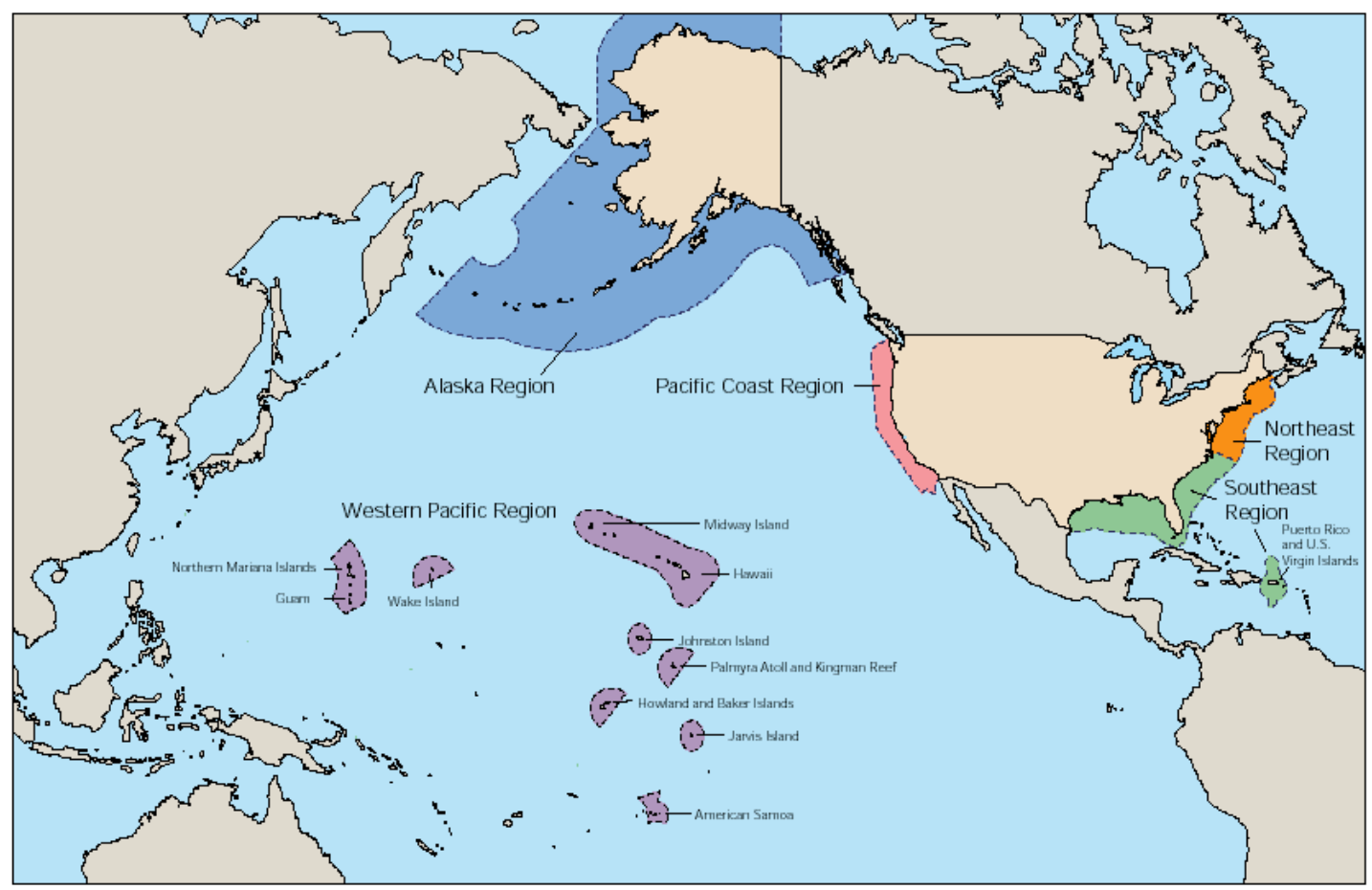

Figure 6. Exclusive Economic Zones off the United States. The North Pacific Fishery Management Council has jurisdiction in the Alaska Region below (figure taken from NMFS 2004a).

To date, the NPFMC has developed five FMP's, which are: (1) the Bering Sea/Aleutian Islands Groundfish FMP; (2) the Gulf of Alaska Groundfish FMP; (3) the Bering Sea/Aleutian Islands King and Tanner Crab FMP; (4) the FMP for the Scallop Fishery off Alaska; and (5) the FMP for the High Seas Salmon Fishery East of 175 degrees East Latitude off the coast of Alaska. The NPFMC is primarily concerned with groundfish stocks of the Bering Sea/Aleutian Islands and in the Gulf of Alaska, and has delegated the management responsibilities for the FMP's regarding king and tanner crabs, scallops, and salmon to the Alaska Department of Fish and Game.

Even though the NPFMC has authority over the Arctic Ocean (e.g. the Chukchi and Beaufort Seas), this council has not drafted any federal FMP's for either 
the Chukchi or Beaufort Seas. Therefore, there is currently an institutional void in the Chukchi and Beaufort Seas in terms of fisheries management. The current FMP's drafted by the NPFMC only cover federal waters south of the Bering Strait, including the Bering Sea/Aleutian Islands FMP (BSAI FMP). Therefore, under a global warming scenario, any species of groundfish that shift north into the Chukchi Sea would not be covered under a federal FMP.

The BSAI Groundfish FMP currently manages all species of groundfish that are commercially fished in the Bering Sea and Aleutian Islands, including walleye pollock, Pacific cod, and some species of rockfish and flatfish (NRC 1999). Vessels use multiple gear types, including trawls, longlines, pot, and jig gear. Most of the catcher vessels and the catcher-processor vessels that harvest groundfish from the BSAI originate from Washington State. Fishermen taking certain groundfish species must adhere to a license limitation plan, while others (e.g. sablefish) are managed under an Individual Fishing Quota Program (NRC 1999).

In 1992 the Western Alaska Community Development Quota (CDQ) program was developed to aid communities in the development of their fishing industries (NRC 1999). The CDQ program allocates a portion of the BSAI total allowable catch (TAC) to coalitions of western Alaskan communities to aid in the development of their communities and their fishing industries. Under this program, communities that had limited economic opportunities due to both geographic isolation and their reliance on subsistence lifestyles could enter into commercial fisheries. Prior to the CDQ program, these communities had historically been excluded from commercial fisheries due to their lack of capital. Initially, these communities obtained a share of the 
pollock fishery; but in recent years portions of other groundfish species, halibut, and crab have also been allocated to these communities (NRC 1999).

The NPFMC's five aforementioned FMP's for fisheries in federal waters have been remarkably successful in ensuring the sustainability of fish stocks in the region. Of the 219 fish stocks managed, only two of these stocks (Bering Sea Tanner Crab and the Blue King Crab at Saint Matthews Island) are considered to be overfished in the entire region under the NPFMC's jurisdiction. Both species are managed under the BSAI King and Tanner Crab FMP's and are currently being rebuilt. Even though two stocks are currently overfished, the NPFMC has the best track record by far of any of the eight regional councils for effective fisheries conservation and management (NMFS 2003).

\section{Federal Management of Subsistence Fisheries in the Bering Sea}

The federal government is not only involved in the regulation of commercial fisheries in federal waters; it is also involved in the regulation of the subsistence fisheries in the Bering Sea. The NPFMC manages halibut on a commercial basis through the IFQ/CDQ Programs, and it also manages the taking of halibut for subsistence purposes. The Alaska Subsistence Halibut Program was launched by the NPFMC in 2003 (68 FR 18145). The NPFMC was given the authority to develop regulations to govern the allocation of the halibut fishery through the North Pacific Halibut Act of 1982. This was an international agreement between the United States and Canada, which states that the NPFMC can develop such regulations as long as they do not conflict with the International Pacific Halibut Commission (IPHC). Under 
the subsistence program, any member of a rural community or federally recognized Alaska Native Tribe that has customarily and traditionally used halibut may harvest halibut for subsistence uses if they have obtained a Subsistence Halibut Registration Certificate, which can be obtained from NMFS (50 CFR Parts 300, 600, and 679).

State Fisheries Management in the Bering Sea

State Management of Commercial Fisheries in the Bering Sea

The Alaska Department of Fish and Game, Division of Commercial Fisheries is in charge of regulating fisheries in state waters - the offshore zone that stretches from 0-3 miles from Alaska's baseline — as well as implementing those federal FMP's featuring a delegation of authority to the state (ADFG 2004d). Species managed in state waters include chinook, coho, sockeye, chum, and pink salmon, Pacific herring, Pacific cod, red and blue king crab, Dungeness crab, clams, shrimp, scallops, sea cucumbers, and sea urchins. These species are caught in a variety of ways, including seines, gillnets, trolls, pounds, pots, trawls, longlines, dredges, and handpicking by divers. The Division of Commercial Fisheries regulates the harvests of these species via gear limits, limited entry, quotas, seasons, and size and sex limits (ADFG 2004d).

The Alaska Department of Fish and Game has a very open system that allows for public input into the management of state fisheries (ADFG 2004a). This openness is attained through the ADFG Board of Fisheries, which is provided with public input through 81 local Fish \& Game Advisory Committees that are distributed throughout Alaska. ${ }^{13}$ The members of these committees are the local experts that provide the

\footnotetext{
${ }^{13}$ This openness can also be seen at the Board's many meetings that are held throughout the state, at which public testimony is permitted.
} 
Board of Fisheries with information on topics important to specific regions. Through these committees, the public can propose changes to fishery regulations, review and comment on fishery management proposals, and aid in the development of management plans (ADFG 2004a).

State Management of Subsistence Fisheries in the Bering Sea

The Alaska Department of Fish and Game, Division of Commercial Fisheries is also responsible for managing state subsistence fisheries (ADFG 2004c), while the ADFG Division of Subsistence is the research branch responsible for collecting the data concerning subsistence harvests (ADFG 2004b). This data is used to facilitate the development of regulations, meet resource management objectives, aid in the development of collaborative agreements, and to assess any environmental impacts of subsistence harvests (ADFG 2004b).

When the State of Alaska has to make resource allocation decisions, subsistence users are given top priority over non-subsistence users (Bosworth 1995). Subsistence management decisions begin with determining how much of the stock can be harvested in a sustainable fashion. After this decision is made, the Board of Fisheries will decide how much of the allowable harvest stock should be given to subsistence users (ADFG 2004a).

In the previous sections, federal and state management of commercial and subsistence fisheries in the Bering and Chukchi Seas was reviewed. Considering the fact that many species of fish are a highly mobile and can cross international boundaries, a discussion of the international aspects of fisheries management is 
warranted. Agreements may need to be made in the future with Russia over fishery resources that move into the Chukchi Sea due to climate change.

International Fisheries Management in the Bering Sea

Any new management regime for the Chukchi Sea may have to take into account international interests, especially with regard to Russia. Currently, there is one major fishery in the Bering Sea that is managed by both the United States and Russia. The boundaries of the Russian and U.S. EEZ's created an unclaimed area in the Bering Sea (known as the "Donut Hole") that was heavily overfished due to the lack of international fisheries management regulations in place. On June 16, 1994 the Convention on the Conservation and Management of the Pollock Resources in the Central Bering Sea was signed in Washington, D.C (NMFS 2004b). There are six signatories: Japan, the Russian Federation, Poland, the United States, and the People's Republics of China and Korea. The primary purpose of this Convention was to curb the overfishing in the Donut Hole region by distant water fishing fleets. This convention has been successful in curbing this overfishing (NMFS 2004b), and shows that new fisheries development in the Chukchi Sea could be regulated via an international agreement.

Future Fisheries Management Directions in the Chukchi Sea

As shown in this chapter, commercial and subsistence fisheries management off Alaska is controlled by a variety of federal, state, and international regulating bodies. This is a reactive fisheries management system in which fisheries are 
developed and then managed for sustainability. The NPFMC has been remarkably successful in the management of fishery resources off Alaska, and commercial fish stocks are abundant (NMFS 2003). However, the Chukchi Sea ecosystem is a pristine environment that has yet to be touched by large-scale commercial development. Any new commercial fisheries development in that region, especially during a stage in which the environment is fluctuating, may be detrimental to the fish stocks moving into the Chukchi Sea. Considering that management off Alaska has been successful thus far, the new management regime could be based on Bering Sea management, except this new management should be proactively developed and planned prior to commercial fisheries development.

Proactive fisheries management may be done in the future by utilizing the concept of reversing the Burden of Proof (Dayton 1998). Conventionally, fishery managers are assigned the burden of showing/proving that a management action is warranted BEFORE managing a species. By reversing the burden of proof, those that want to exploit public marine resources would have to prove that their actions are not detrimental to the fish stock, rather than just assuming their actions are benign until proven otherwise. The reversal of the burden of proof is a concept that is not actually in practice, but it could be used in the Chukchi Sea as an alternative to simply allowing fishing to develop. Therefore by reversing the burden of proof in the Chukchi Sea, fish stocks would be protected with management from the beginning, rather than implementing management after the damage has been done (Dayton 1998).

New proactive commercial fisheries management could also be supplemented with the precautionary approach towards managing fisheries. The NPFMC already 
uses the precautionary principle in the management of its fishery resources (Witherell et al. 2000). In theory, the precautionary approach ensures that decisions are not made that would have long term adverse effects; it incorporates uncertainty within the fishery into management decisions; it is often used in data-limited situations; it allows for adaptability to new situations; and it ensures that catch limits are set at levels that will not be detrimental to other species. When using the precautionary approach, the higher the level of uncertainty, the more cautious managers should be (Parkes 2000; Young 1998). Therefore, if the precautionary approach was used in the Chukchi Sea, this area would be opened slowly to commercial fisheries development and the harvest levels would be very low in the beginning.

New management of fish stocks moving into the Chukchi Sea could either be an extension of the current reactive fishery management system used in the Bering Sea, or it could be a combination of Bering Sea management and new concepts such as proactive fisheries management, the Burden of Proof, and the precautionary approach. In Chapter 5, the results of the formal and informal interviews with fishery managers will be presented. Their responses will highlight what physical and social scientists and fishery managers think should be done in response to potential shifts of fishery resources into the Chukchi Sea. 


\section{Chapter 5}

Results

In Chapters 1-4, background material was presented on the biology, humans, and fisheries management system in Alaska in order to provide an understanding of why fisheries managers may encounter a problem in the future if the current warming trend continues. Continued warming could not only impact the effectiveness of fisheries management in Alaska, but it could also affect Alaska Natives if fisheries are not developed in a sustainable and ecosystem-friendly manner.

As outlined in the methods section in Chapter 1, the main body of research for this thesis was gathered by: 1) attending conferences and informally interviewing conference attendees in Washington, D.C. and in Fairbanks, Alaska; and 2) conducting a series of formal interviews with seven state and federal fishery managers and one Academic professional in Anchorage and Juneau, Alaska. The purpose of asking the seven research questions in the formal interviews was to: 1) ascertain the current level of awareness, concern, and planning by federal and state resource managers in Alaska for the potential for commercial fisheries expansion; 2) determine what future fisheries management regime would be appropriate for the Chukchi Sea region; and 3) determine how Alaska Natives could be involved in a new fisheries management regime.

Since this thesis is based on the assumption that sea ice will continue to retreat as temperatures warm in the coming years, an examination of the most up-to-date climate research was needed. This examination was accomplished by attending the 
annual meeting of the Arctic Research Consortium of the United States (ARCUS) in Washington, D.C. from May 13-14, 2004. The theme of this conference pertained to global climate change and the recent decline of sea ice. Approximately 100 physical scientists from around the world attended. Knowledge was acquired on the current and potential future state of sea ice in the Arctic. Informal interviews ${ }^{14}$ were conducted with attendees to determine: 1) what the future climate could be in Alaska; 2) if the current warming trend and decline of sea ice in Alaska is due to natural or anthropogenic causes; and 3) if there should be any planning underway to prepare for shifts in commercial fisheries. The results of this conference will be presented in Section I of this chapter.

In order to understand how Alaska Natives might be affected by global climate change and shifting fisheries, a second conference was attended in Fairbanks, Alaska from May 19-23, 2004. The theme of this conference pertained to Arctic Native peoples and the current issues affecting their populations. This conference was attended by approximately 400 social scientists from around the world who conduct research in Native communities. While at this conference, sessions were attended and social scientists were informally interviewed to determine whether Alaska Natives would be affected by new fisheries development and how they could be involved in the fisheries management process. The results of this conference will be presented in Section II of this chapter.

Physical and social scientists at the ARCUS and ICASS V conferences provided information pertaining to climate change, sea ice, and whether Alaska

\footnotetext{
${ }^{14}$ Informal interviews with attendees served two purposes: 1) to clarify specific points made within conference presentations; and 2) to ask respondents specific research questions related to their expertise.
} 
Natives would be affected by new fisheries development in the Arctic due to climate change. While attending the sea ice conference, it was noted that physical scientists were dissatisfied with politicians on the amount of planning being done to prepare for an Arctic Ocean that is likely to lose a drastic amount of sea ice in the next few decades. At the social science conference, it was noted that climate change is presently affecting Alaska Natives, and that any new fisheries development in the Chukchi Sea would need to be carefully planned with Natives' interests in mind.

The information gained at the two conferences was helpful in determining the current and potential future state of sea ice in Alaska and whether Native peoples would be affected by new fisheries development in the Chukchi Sea. However, the information gained while in the sessions and from the informal interviews lacked a fisheries management perspective. Therefore the third section of this research was devoted to interviewing state and federal fisheries managers in Alaska to determine three things: 1) do resource managers believe they should be planning for fisheries expansion due to climate change; 2) how will those fisheries be managed if they expand into a new area such as the Chukchi Sea; and 3) how will Alaska Natives be affected, and how could they be involved in new fisheries management in the Chukchi Sea. The results of these interviews will be presented in Section III of this chapter.

\section{Section I: What do Physical Scientists Think?}

The purpose for attending the ARCUS annual meeting in Washington, D.C. on sea ice and climate change was to determine the answers to three questions, as well as to make contacts with sea ice scientists and gain further knowledge on the current 
issues pertaining to global warming and the recent reduction of sea ice. Physical scientists were asked the following two questions:

1) What will the Arctic Alaskan climate be like in the coming decades?

2) Is the current warming trend and decline of sea ice in Alaska due to natural or anthropogenic causes? Will this trend in sea ice retreat reverse itself naturally in the coming years?

Eleven informal interviews were conducted with attendees of the ARCUS $16^{\text {th }}$ Annual Meeting. Of particular interest were two interviews that went beyond questions on climate science and into the political science sector. These two respondents were presented with a third question, which will be elaborated later in Section I. The third question is as follows:

3. Should planning be underway to prepare for northward shifts in commercial fish species?

The presenters and attendees at this conference provided the answers to the three questions listed above. First and foremost was the answer to the first question on what the future climate in Alaska might resemble in the coming decades. 
What will the Arctic Alaskan climate be like in the coming decades?

The nineteen presenters fully recognized that the climate of Alaska has warmed extensively and it will continue to warm in the future. The presenters did not debate the fact that the extent and volume of Arctic sea ice has decreased extensively in the past few decades. Sea ice has not only decreased in both extent and volume, but this decrease is now accelerating in pace.

A sense of urgency was conveyed by climatologists who presented conservative models showing that Arctic sea ice could disappear by the year 2013. Very large areas of open water are now present during the summer months in the Beaufort Sea, and three of the past six summers had the smallest extent of Arctic sea ice ever recorded. In the future, sea ice extent and thickness is likely to continue on this declining trend, especially since large temperature increases are now occurring over Northern Canada and Alaska. The warming trend is predicted to continue throughout the $21^{\text {st }}$ century, which could result in distributional shifts of terrestrial and marine biota into the Arctic from southern regions (Serreze 2004).

Is the current warming trend and retreat of sea ice due to natural or anthropogenic causes, and will this warming trend continue in the coming years?

The second question answered by attending this conference was whether or not the atmospheric warming trend and retreating sea ice is due to natural or anthropogenic causes, and whether it will naturally reverse itself in the coming years. An important point that came out of this conference is that sea ice extent varies naturally with changing global cycles; however, when the current global warming 
trend was analyzed and this natural variation removed, an increase in the global temperature still occurs. Many climatologists believe that this increase in temperatures is due to anthropogenically-induced global warming caused by the influx of greenhouse gases into the atmosphere. Unless the concentration of atmospheric greenhouse gases is reduced, the Arctic climate will likely continue to warm.

This conference also answered the second part of the second question on whether the current declining trend in sea ice will naturally reverse itself in the coming years. Temperature patterns naturally shift from warm to cool due to changes in atmospheric oscillation patterns (as discussed in Chapter 2). However, in the North Atlantic, a recent shift of the North Atlantic Oscillation (NAO) from a positive to a neutral state normally would have resulted in a shift from a warmer to cooler state. Even though this shift to slightly cooler temperatures has occurred, the analysis of long-term temperature data has revealed that the climate is still warming in the north. Therefore a shift naturally occurred within the atmosphere that should have caused a reversal of the decline in sea ice; however, the sea ice is still declining. This could be an indication that greenhouse gas concentrations are high enough in the atmosphere to impede the natural reversal of temperatures to a cooler state in the Arctic.

Another interesting point about this warming trend is that it is a global and not a regional phenomenon. In the 1920's the North Atlantic underwent a regional warming trend, however, adjacent areas did not warm during this time period. This supports the theory that temperatures are warming due to humans, and unless greenhouse gases are capped the temperatures will continue to rise as humans continue to burn fossil fuels. 
Beyond the primary purposes for attending this conference, a third unexpected but interesting outcome resulted from attending this conference. Discussions of Arctic atmospheric and biological sciences were meshed with politics towards the end of the meeting. A heated panel discussion revealed the frustrations of climate scientists towards policy-makers for not addressing the urgency of climate change and the reduction of sea ice. Of particular interest were the discussions over why planning for this reduction in sea ice has not been done, and why it is pertinent to the future of Arctic ecosystems and human populations. The lack of planning with regards to opening the Arctic Ocean to transportation, oil and gas development, tourism, and commercial fishing could result in major problems if policies and plans are not developed in advance.

Should planning be underway to prepare for northward shifts in commercial fish species?

A presenter at the ARCUS meeting spoke specifically about the potential for an increase in commercial fishing activity due to sea ice retreat in the southern Chukchi Sea (the subject area of this thesis). In an informal interview, the respondent explained that the large population of whales in the Chukchi Sea could be adversely affected by a northward expansion of commercial fishing fleets. The whales and fishermen would not only compete for food, but there would likely be an increase in the number of both human interactions and entanglements in fishing nets. The third question listed above was presented to this respondent on whether planning should be underway to prepare for potential shifts in commercial fish species. The respondent 
responded by stating that a plan should be developed now to deal with any expanding fisheries or new fisheries development in the Chukchi Sea. The respondent also felt that the Alaska Natives would have to be involved in the development of a new fisheries management regime and suggested that the Community Development Quota (CDQ) program could be used to involve Alaska Natives residing adjacent to the Chukchi Sea. The CDQ program is currently used in the Bering Sea region and provides a way for Alaska Natives to be involved in commercial fisheries (NRC 1999).

A second informal interview with a political scientist was also interesting because the respondent believed that many governments are politically ill-prepared for climate change in the Arctic. The respondent supported the physical scientists by stating that policy-makers are not ready for climate change even though the scientists have provided policy-makers with sufficient information upon which to base their decisions. The respondent believed that policy-makers often have a tendency to say that climate change is not a problem and they will not take action until it is absolutely necessary. This lack of action is due to the fact that: 1) there would be a limited political impact due to the small number of stakeholders in the Arctic; 2) they do not completely understand the problem of climate change; and 3) any action taken now will be expensive. The third question listed above was also presented to this political scientist in the informal interview. The respondent was adamant about pushing a policy through on climate change (such as the Kyoto Protocol), and strongly recommended that any commercial fisheries that develop in new areas be proactively planned and regulated prior to any exploitation. 
Overall, this conference answered some lingering questions on climate change as well as provided the opportunity to make contacts with eleven major climate scientists from around the world. Climate is warming and it is expected to continue to warm due to anthropogenic causes, which could result in major problems if the Arctic Ocean opens to development. This warming trend is not expected to reverse itself because a natural climate shift already occurred, and the long-term temperature plots reveal that climate is still warming. Climate scientists urged that a policy be developed and implemented to curb worldwide greenhouse gas emissions, and many believe that planning for the reduction of sea ice should be done now before the Arctic Ocean is open completely.

The ICASS V conference attended in Fairbanks, Alaska from 19-23 May 2003 on Arctic social sciences provided information on Alaska Natives and the issues currently faced by their societies. This information will be presented in results Section II.

\section{Section II: What do Social Scientists Think?}

The purpose of attending the $5^{\text {th }}$ International Congress on Arctic Social Sciences was to: 1) gain further knowledge of the issues currently pertinent to Native peoples; 2) to determine if Alaska Natives will be affected by fisheries development in the Arctic; and 3) to determine how Alaska Natives can be involved in a new fishery management regime in the Chukchi Sea. Knowledge of the issues currently pertinent to Alaska Natives was gained by attending the conference sessions. Ten social scientists were then informally interviewed to clarify lingering questions from their 
presentations and then were posed two questions pertaining to fisheries development and new fisheries management in the Chukchi Sea. The two questions posed were:

1) Will Alaska Natives be affected by commercial fishing fleets moving into northern areas due to shifting fisheries and climate change? If so, how?

2) How do you think Alaska Natives could be involved in the management process for developing fisheries in new areas such as the Chukchi Sea?

Of the ten social scientists informally interviewed, three respondents were both social scientists and Alaska Natives that were raised in Native communities. The respondents represented a variety of universities and agencies, including: 1) Department of Anthropology, Oregon State University; 2) National Park Service; 3) Helsinki University of Technology; 4) Inuit Circumpolar Conference; 5) University of Washington; 6) University of Alaska Fairbanks; 7) University of New Hampshire; 8) a former teacher in the Alaska Native community of Chefornak; 9) Alaska Department of Fish and Game; and 10) University of Alaska Anchorage.

\section{Current Alaska Native Issues}

While attending the sessions, knowledge was gained on the current issues pertinent to Alaska Natives' societies. Natives are concerned with a wide variety of issues pertaining to the sustainability of their resources, social conditions within communities, gender issues, politics, local knowledge, retaining their traditional language, maintaining order and stability, preserving their culture, and the effects of 
climate change on infrastructure and on their subsistence lifestyles. At the present time, the warming trend is amplified in the Arctic, and Alaska Natives are being affected by climate change more than many other people in this world. Global warming has resulted in a change in temperatures unlike anything the Natives living in Alaska have previously seen. In the summer months, the northern Bering, Chukchi, and Beaufort Seas typically remain ice free for a few months of the year. However, Alaska Natives have made many observations in recent years of less resident and less stable sea ice in winter, melting permafrost, and of new species coming into their area (Krupnik 2000a; 2000b). The most interesting piece of evidence for new species came from a session on language. As new species move into new areas, Alaska Natives have to create new words within their language to identify those species because their old language does not contain words describing them (Henshaw 2004).

A major issue that is affecting Alaska Natives is the instability and loss of sea ice due to climate change. Sea ice is used as a platform from which to hunt marine mammals, so when sea ice retreats quicker and is less stable, it cannot be relied upon to access their traditional food. This inaccessibility to marine mammals by Native walrus hunters has resulted in an increase in technology within their villages because aluminum boats with outboard motors have been purchased to reach the ice edge. The hunters now have to travel thirty miles offshore to hunt walrus that they had always been able to hunt close to their villages (Anungazuk 2004). Walrus are ice-dependent mammals, so as the sea ice retreats farther north these mammals will shift their distributions farther into the Arctic. After a while, it may not be economical for these Natives to hunt marine mammals such as walrus, but it may be economical for them to 
harvest commercial fish that are also shifting their distributions north into areas closer to their communities. Alaska Natives of the Chukchi Sea would need more capital to harvest commercial fish species, so a program could be developed that provides the means by which these Native peoples can enter commercial fisheries. In the Bering Sea, the Western Alaska Community Development Quota (CDQ) program has been developed that provides this means (NRC 1999), and could perhaps be expanded into the Chukchi Sea if commercial fisheries develop in that region. In the following paragraphs, the two questions posed to the ten social scientists on fisheries expansion due to climate change will be discussed.

Will Alaska Natives be affected by commercial fishing fleets moving into northern areas due to shifting fisheries and climate change? If so, how?

The answers given were fairly general, which is partially due to the fact that many of the interviewees were not resource managers; they were social scientists. In response to question \#1, all ten respondents believed that Alaska Natives would be affected by fisheries development in northern areas in some way. These effects were both positive and negative, and many respondents believed that a combination of positive and negative effects would occur. Negative effects due to fisheries development include the disruption of whale migration routes, disruption of the food web, competing with resources that the Natives depend upon for their subsistence lifestyles, an increase in vessel noise in areas where whales are harvested (in effect, changing the distribution of species), releasing pollution in the Chukchi Sea that would be harmful for marine resources, and generally effecting the culture of Chukchi 
residents due to commercial development. Positive effects due to fisheries development include an increase in jobs, revenue, and infrastructure in coastal communities in the Chukchi Sea region.

The effects of commercial fisheries development on Alaska Natives would likely be a mix of positives and negatives. Native peoples may want to conserve and protect their traditional resources, but their economies are suffering (Callaway 1998) and they may welcome the extra revenue. The marine resources that could be affected by commercial development can only be harvested if the communities have a source of cash to fuel their boats and snowmachines. Therefore some negative effects on marine resources may have to be balanced with development of commercial fisheries in order to maintain Native subsistence lifestyles. In any case, respondents believed that Alaska Natives should be involved in the management of new fish stocks moving into the Chukchi Sea region due to climate change.

How do you think Alaska Natives could be involved in the management process for developing fisheries in new areas such as the Chukchi Sea?

When the respondents were posed the question on how to involve these peoples in management, six people did not have the background to speculate on the management aspect because their expertise was not in fisheries management. Of the four people who responded to the second question, two mentioned that the communities could be involved through the use of the CDQ program (NRC 1999). One respondent believed that meetings and workshops could be used, and the last respondent believed an international approach should be used via the involvement of 
the Inuit Circumpolar Conference (ICC) (Bloom 1999). The ICC is an international organization that is involved in ensuring the rights of Native peoples throughout the Arctic. It is a permanent participant of the Arctic Council, which was created by the eight states that have territorial sovereignty in the Arctic. Those states are Canada, Finland, Iceland, Norway, Russia, Sweden, the United States, and Denmark. The two major objectives of the Arctic Council are to promote environmental protection and to encourage indigenous human populations to develop their resources sustainably (Bloom 1999).

Overall, the answers given at this conference imply that Native communities would likely be affected by commercial fisheries development in the Arctic, and these communities should be involved in all management decisions. The effects of commercial fishery development could either be positive, negative, or mix of each. Alaska Natives could be involved through the use of the CDQ program, workshops and meetings, or through the use of an international organization such as the ICC. The irony of these responses is that the CDQ program and the ICC do not really "involve" Alaska Natives in fishery management. The ICC does not manage fisheries in Alaska (or elsewhere), and although the CDQ program allows Native peoples to enter the commercial fishing industry, it does not actually involve them in the management decisions. The regional corporations representing Native peoples are just allocated a share of the total allowable catch (NRC 1999). If a similar program developed in the Chukchi Sea, this shortcoming could be resolved by allowing Alaska Natives to make management decisions for fish stocks moving into their region. The lack of 
"involving" Alaska Natives in the fishery management process will be further elaborated in Chapter 6.

So far, the perspectives of physical and social scientists have been discussed. In the next section, the results of interviews conducted with state and federal resource managers in Alaska will be presented. These next interviews will complete the research done for this thesis by presenting the perspectives of seven fishery managers and one Academic professional with first-hand knowledge of the Chukchi Sea region.

\section{Section III: What do Fishery Managers Think?}

This section will present the results of the interviews conducted with state and federal resource managers and one Academic professional in Alaska. Nine total interviews were conducted in Anchorage and Juneau, Alaska from May 24-28, 2004. Ten people were interviewed due to the fact that two people attended one interview. Of the nine interviews, one of these interviews will not be included in this thesis due to non-responsiveness. ${ }^{15}$ This interview contained two people, so the total sample size will be eight interviews with eight different people.

These eight interviews were conducted with seven federal and state fishery managers, and the remaining interview was conducted with an Academic professional with first-hand knowledge of the Chukchi Sea region. Of the eight interviews, six were conducted in Anchorage and two were conducted in Juneau, Alaska. The Anchorage and Juneau interviews were conducted with representatives of the following agencies/organizations: 1) North Pacific Fishery Management Council; 2)

\footnotetext{
15 "Non-responsiveness" means that the respondents would not answer any of my research questions and therefore could not be included in the data analysis.
} 
National Marine Fisheries Service; 3) Alaska Department of Fish and Game; 4) Norton Sound Economic Development Corporation; 5) North Pacific Research Board; and 6) University of Alaska, Anchorage.

Seven questions were presented during the formal interviews. The seven research questions were grouped into three themes for the purpose of this analysis. These three themes pertain to: 1) planning for fisheries expansion due to climate change; 2) future fisheries management in the Chukchi Sea due to climate change; and 3) the impacts of fisheries development on coastal Chukchi Sea communities. These themes will be presented sequentially in subsections A, B, and C. Subsection A will be presented in the following paragraphs, which addresses the first theme listed above.

\section{Subsection A: Planning for Fisheries Expansion}

In the formal interviewing process, fishery managers and the Academic professional were posed with the following two questions in regards to planning for fisheries expansion due to climate change:

1. Given the current rate of global climate change, do you think fishery managers should be planning for shifts in species, and why do you feel this way?

2. If you believe that there should be planning, what type of planning should be done?

In seven of the eight formal interviews, respondents stated that there should not be any planning right now for fisheries shifts. Three of the seven respondents 
stated that even though there should not be planning right now, there should be some planning done in the future if species start moving north in large numbers. Until that happens, resource managers should address current issues rather than plan for what may happen in the future. When the seven respondents were asked why they felt planning should not be done at the present time, some common themes resonated throughout their responses. The most common reasons why respondents answered negatively toward planning are as follows:

1. Planning for fisheries shifts would be very hard to do right now.

2. Policy makers will have a better indication from science on what is going on in the ecosystem in the future, so planning should not be done now.

3. Fisheries shifts will not be instantaneous; rather, they will be gradual and not resemble the rapid ecosystem responses seen in El Nino years.

4. Policy makers would have a little bit of a planning horizon unless a huge shift occurred within a short period of time.

5. Fisheries management is adaptive, so the system would adapt to any changes and planning is not needed.

6. When you plan for something, it may make it up the chain of command and eventually become an unfunded mandate. Agencies do not want unfunded mandates.

One respondent answered positively towards planning for fisheries shifts due to the fact that climate and species are beginning to change in the Alaska region. This 
respondent and the three respondents who answered positively for planning in the future (but not at the present time) were asked what type of planning they thought should be done. The following is a compilation of the types of planning the four respondents thought should be done either now or in the future.

1. Planning for potential northward shifts of commercial fisheries by increasing the amount of research done in northern areas. This research could encompass:

a. Keep looking into the distribution and extent of sea ice.

b. Keep observing bottom temperatures and increase the number of ocean observation systems. Use these systems to look at the water column over time to see if the cold pool is dissipating.

c. Fund experimental trawling to see where the fish are now, and then use this information as baseline information. This northern trawling could take place every few years throughout the upper Bering Sea/ Chukchi Sea.

d. Look at other animals within the food web to see how they are affected by any shifts in fisheries.

2. Planning for an accurate measure of harvest to be developed in the area

3. Planning for new interest in sports fishing

4. Planning for adverse effects on subsistence users

5. Planning for the development of a new CDQ group 
6. Planning for an increase in transportation due to commercial fishing and shipping vessels

7. Planning for an increase in exotic species in new areas due to ballast water

8. Plan to not develop the Chukchi Sea for commercial purposes

The most common response given by three of the four respondents was to plan for more research now and in the future. The seven other responses to the "planning type' question (question \#2 above) were given by one respondent. Plan \#8 that suggests the Chukchi Sea should not be developed for commercial purposes sheds light on the fact that Native peoples may not want these areas to be developed. Even though coastal communities along the Chukchi Sea coast may benefit from fisheries development in former ice-covered areas (which is addressed later in this results section), some Alaska Natives may feel the risks to their subsistence lifestyles and on the biota of the region is too great to quietly allow development (e.g. potential impacts on migrating bowhead whales by commercial fishing vessels). This point is further explored in the Alaska Natives section of results section III.

Overall, the respondents did not believe planning should be done to prepare for northward shifts in fisheries due to the retreat of sea ice and warming ocean temperatures caused by global climate change. The lack of concern over planning for the effects of climate change on fish stocks was primarily due to the fact that shifts are perceived to be a gradual process that is far in the future. However, as was seen in Section I of this results chapter, global climate change is indeed real and occurring 
very rapidly, and changes in fish distributions have already been documented in the Bering and Chukchi Seas (Krupnik 2000a).

If any planning is to be done, it is likely to occur in the research sector. Research planning may include scheduling a larger number of experimental trawling trips into northern areas, increasing the number of ocean observation systems to detect further changes in the water column, continuing the monitoring of sea ice via satellites, and by monitoring the food web in the Bering and Chukchi Seas.

The next subsection (B) of Section III will discuss how these new areas may be managed in the future. The eight respondents were presented with two questions pertaining to the Chukchi Sea on how this new area might be managed in the future if the area is opened due to global climate change.

\section{Subsection B: Future Fisheries Management in the Chukchi Sea}

In the formal interviewing process, the respondents were asked the following two questions (question \#3 and \#4 in the interviews) with regard to future fisheries management in the Chukchi Sea due to climate change:

3. If fisheries shift into new areas such as the Chukchi Sea (which could be a problem because the federal FMP's in place do not cover commercial fish species in the Chukchi Sea), how do you think this development should be managed, and who should oversee this management? 
4. Should this management be developed prior to allowing fishing in those areas to control the amount and type of fishing done by fishermen that are exploring new areas?

Of the eight interviews conducted, one of the respondents did not answer this question due to his lack of comprehensive knowledge of fisheries management off Alaska. The remaining respondents had sufficient knowledge of fisheries management off Alaska, and therefore were able to answer both questions above. Question \#3 is broken down into two parts: (1) What should fisheries management look like in a new region such as the Chukchi Sea; and (2) Who should oversee this management? Question \#4 pertains to the dilemma managers could face regarding whether or not to develop a regulatory system prior to exploratory fishing for the purpose of preventing overfishing before it begins in the Chukchi Sea. The following sections outline the major results found when respondents were asked question \#3 and \#4 above.

What should fisheries management look like in a new region such as the Chukchi Sea?

Several ideas emerged on what fisheries management might look like in an area such as the Chukchi Sea, which has not been managed for large-scale commercial fisheries in the past. Overall, respondents believed that any fish stocks that move into the Chukchi Sea could be managed by:

1. Developing new FMP's to cover species shifting into the Chukchi Sea. 
2. Extending the jurisdiction of the current FMP's into the Chukchi Sea.

3. Developing a treaty with Russia to jointly manage fisheries in the Chukchi Sea

4. Developing a plan to keep the Chukchi Sea free of fishing activity, thereby deciding not to develop fisheries in this new area

The seven respondents primarily responded with the first two management options. A majority (4) of the respondents believed that new FMP's should be developed to manage species shifting into the Chukchi Sea. Two of the respondents believed that either of the first two management options could occur; therefore new FMP's could be developed or the jurisdiction of current FMP's could be extended into the Chukchi Sea. The remaining respondent believed that the current FMP's in place would be sufficient, and that an amendment would suffice to extend the FMP's into the Chukchi Sea.

Besides developing new FMP's or extending existing FMP's, four of the seven respondents mentioned that international problems could arise with Russia due to the fact that the Chukchi Sea is almost entirely covered by the EEZ's of Russia and the United States. Management would thus be easier because most of the water in the Chukchi Sea is not considered "high seas," and would not be subjected to distant water fishing fleets from around the world (Von Glahn 1996). However, Russia typically harvests younger fish that have yet to substantially contribute to the population (Freese 2000). Therefore an international regime should be considered in this area to ensure U.S. conservation efforts are not undercut by Russian fishing policies. 
One respondent mentioned that it may be of interest to the United States to choose not to develop fisheries in the Chukchi Sea due to the potential impacts on the Native population residing along the coast. Although Chukchi residents have never relied on some of the major commercial stocks such as pollock, any fishing vessels entering the area may pose a wide array of environmental impacts. These impacts include pollution, interactions with marine mammals, and the impact of species removals on the marine ecosystem. The next section pertains to the second part of question \#3, which asks who should oversee new management in the Chukchi Sea.

Who should oversee the management of fisheries shifting into the Chukchi Sea?

At the current time, the North Pacific Fishery Management Council (NPFMC) holds jurisdiction over commercial fisheries in the Exclusive Economic Zone off Alaska (MSFCMA, P.L. 94-265, § $302(\mathrm{G})$ ). Six of the seven respondents believed that the NPFMC would continue to manage fish stocks in the waters off Alaska. Of these six respondents, two mentioned that if the NPFMC lacked the funds or the interest to manage new fisheries development in the Chukchi Sea, the State of Alaska could manage fishing vessels that move into new areas that do not have federal FMP's, such as the Chukchi Sea. The State of Alaska is given this right in the MSFCMA (MSFCMA, P.L. 94-265, § 306 (a) (3) (A)).

The remaining respondent chiefly believed that the area would need to be managed by a regional management body. The governing body would need to reflect the relevant users and authorities in the region, such as the State of Alaska and the U.S. and Russian governments. There should be a mix of commercial, recreational, 
and subsistence representatives in this regional management body to allow input from existing and potential new user groups of the region. This idea was also mentioned by another respondent, although he chiefly believed that the NPFMC would be responsible for managing fisheries in the Chukchi Sea. The next section presents the results of question \#4, which asks whether or not a regulatory system should be developed prior to exploratory fishing in the Chukchi Sea.

Should a proactive management regime be put in place prior to exploratory fishing?

The results to this question were surprising. In the face of emerging literature on the downfalls of reactive fisheries management (Dayton 1998), the respondents did not choose a proactive approach towards managing fisheries in a new area. Of the seven respondents that regularly address fishery management issues, only two said that management should be developed prior to exploratory fishing. The remaining five respondents believed that management should be developed after fisheries developed in the Chukchi Sea region. Of these five respondents, three of them specifically stated that this is due to the reactive nature of fisheries management in Alaska.

Overall, the respondents believed that future management in the Chukchi Sea would be overseen by the North Pacific Fisheries Management Council with a potential for a more regional management approach by a multi-sectoral governing body. Managers would likely develop new Fishery Management Plans after exploratory fishing develops in the Chukchi Sea. International issues could be 
resolved by developing a treaty with Russia that specifies the type and amount of fishing permitted within this new fishing area.

In Subsection B, the future management of fish stocks moving into the Chukchi Sea was discussed. The remaining subsection of Section III will discuss the avenues by which Alaska Natives could be involved in the management of new fisheries off their coasts.

\section{Subsection C: The Effects of Fishery Development on Coastal Chukchi Sea}

\section{$\underline{\text { Communities }}$}

In the formal interviewing process, I asked the respondents the following three questions (questions 5-7 in the interviews) with regard to how Alaska Natives could be involved in the management of fisheries that develop in the Chukchi Sea due to the retreat of sea ice and warming ocean temperatures. All of the eight people interviewed had sufficient knowledge of the Native peoples residing in coastal communities on the Alaska shoreline, so all eight of the responses were analyzed in this section.

5. If fisheries shift into new areas, do you think Native communities would be affected by the presence of commercial fishing fleets off their coasts?

6. How do you think Alaska Natives could be involved in the management process for developing fisheries in new areas such as the Chukchi Sea?

7. Who should be involved in this management? 


\section{Effects of Commercial Fisheries Development on Alaska Natives}

In response to question $\# 5$ on whether or not Native coastal communities would be affected by the presence of commercial fishing fleets off their coasts, all eight of the respondents believed that Native coastal communities would be affected by these fleets moving into the Chukchi Sea. Of these eight respondents, four believed that the communities would be positively affected by new commercial fisheries development and would likely welcome this new development, especially in Kotzebue, Alaska. This is due to the fact that when the Community Development Quota program was initiated, the residents of Kotzebue tried to be included in the Norton Sound Economic Development Corporation (NSEDC), which is the northernmost CDQ group. However, only coastal communities within fifty miles of the Bering Sea are permitted within the NSEDC, so Kotzebue was not included and thus lost an opportunity to economically enhance the community.

The other four respondents felt that there would be a mix of positive and negative effects on the communities. These respondents felt that if fisheries were developed in the Chukchi Sea, the communities would likely benefit economically by this development. However, the respondents also believed that this development could have negative effects on Alaska Native cultures if bowhead whales were affected or their subsistence lifestyles altered.

Upon analysis of the interviews, it was determined that none of the respondents believed that fisheries development would have a solely negative affect on the coastal communities in the Chukchi Sea region. Four believed Alaska Natives 
would be positively affected, and the other four believed there would be a mix of positive and negative effects.

Involvement of Natives in Fisheries Management in the Chukchi Sea

The purpose of question \#6 was to determine how Native peoples could be involved in the management of fisheries that develop in the Chukchi Sea in the future. The primary responses were as follows:

1. Involve Native peoples through the CDQ program. This would occur by either developing a new CDQ group in a new Fishery Management Plan for the Chukchi Sea or extending the current CDQ program for the Bering Sea by putting Chukchi communities into current CDQ groups.

2. Manage fisheries jointly between resource managers and Alaska Natives through a co-management agreement.

Of the eight people interviewed, six responded to question \#6 with the first management option above. The six people believed that Alaska Natives could be involved in fisheries management via the CDQ program. Of these six people, three respondents believed that a new CDQ group should be developed. The other three people stated that either a new CDQ group should be developed or the Bering Sea CDQ program should be extended into the Chukchi Sea, with communities incorporated into the current CDQ program for the Bering Sea. The seventh respondent believed that a combination of co-management and the use of the CDQ 
program would be sufficient to include Alaska Natives in new fisheries. The eighth respondent believed that co-management would be an acceptable method, just as long as Natives were involved via the least confusing way possible.

When the eight respondents were asked who should be involved in this new management (question \#7), all eight responded by stating that all communities along the Chukchi Sea coast should have a say in any new management due to the fact that many of these communities subsist on resources they obtain from the ocean. As was seen by the results of question \#6 on how Alaska Natives could be involved in fisheries management, seven of the respondents stated that the CDQ program could be used. To be eligible for involvement in the Western Alaska CDQ program, a community must be located within fifty miles of the Bering Sea coast and show historical reliance on marine resources (MSFCMA, P.L. 94-265, § 305 (i) (1) (B)). Since communities in the Chukchi Sea region are greater than fifty miles from the Bering Sea coast, the MSFCMA would have to be amended to incorporate these communities within the Western Alaska CDQ program.

Overall, the results presented in this subsection show that managers believe that Alaska Natives are likely to be affected by the presence of commercial fishing fleets that move into the Chukchi Sea. These effects are likely to be either positive or be a mix of positive and negative effects. It is important to note that none of the eight respondents believed that the effects would be completely negative for the communities. If fisheries were developed in the Chukchi Sea, communities could most likely be involved in any new management through the use of the CDQ program. One of two things would occur: 1) a new CDQ group would be developed; or 2) the 
current CDQ program for the Bering Sea would be extended into the Chukchi Sea and any new communities would be incorporated into existing CDQ groups. All coastal communities within fifty miles of the Chukchi Sea could be involved in this new management.

\section{Conclusion}

This research provided an opportunity to attend two large conferences and interview resource managers, physical scientists, and social scientists from around the world. In total, thirty-one people were informally or formally interviewed, who represented twenty-four different universities, international organizations, agencies, and foreign governments. Thirteen people were interviewed representing ten different universities, with eight universities from the United States, one from Finland, and one from Canada. Four people representing four different Native people's organizations were interviewed. One person from a research funding organization was represented in this sample. Eight people were interviewed within four federal/state government agencies involved in the resource management process, including economics, fisheries science, Native peoples perspectives, and management and policy. Two climate scientists were interviewed that represented the Canadian government, and another climate scientist was interviewed from an independent laboratory. The remaining two people were independents, one of whom was an author, and the other was a former teacher in an Alaska Native village. Of the thirty-one people sampled, twelve contributed to Native peoples perspectives, eleven contributed a physical biology perspective, and eight contributed to a policy and management perspective. 
The questions asked throughout the thirty-one interviews pertained to three central themes: 1) should there be planning; 2) what would future management look like in the Chukchi Sea; and 3) how could Alaska Natives be involved in this new management? With regards to planning, the results obtained were interesting in that the sea ice scientists believed that there should be a strong push towards planning for climate change. Many believed that planning should be done now before the Arctic Ocean is open completely. However, resource managers thought less of planning and more for dealing with the current situation at hand. Thus if any planning is to be done, it is likely to occur in the research sector.

With regards to future management in the Chukchi Sea region, resource managers believed that future management in the Chukchi Sea would be overseen by the North Pacific Fishery Management Council. Managers would likely develop new Fishery Management Plans after exploratory fishing develops in the Chukchi Sea. International issues could be resolved by developing a treaty with Russia that specifies the type and amount of fishing permitted within the new fishing area.

With regards to Alaska Natives, the majority of respondents believed that Native peoples would likely be affected if commercial fisheries were developed in the Chukchi Sea. Communities could be involved in new management through the use of the CDQ program, so one of two things would occur: 1) a new CDQ group could be developed; or 2) the current CDQ program for the Bering Sea could be extended into the Chukchi Sea and any new communities would be incorporated into existing CDQ groups. 
The results of this thesis show that fishery managers are not planning for shifts in the distributions of fish stocks due to climate change. If climate change results in a distributional shift in fish stocks, fishery managers will develop FMP's after the inception of exploratory fishing. Alaska Natives living in the Chukchi Sea region could be involved in commercial fisheries through the use of the Western Alaska CDQ program. This indicates that any new management needed in the Chukchi Sea would basically be an extension of current fishery management. In an era where fishery managers are realizing that mistakes made in the past were partially due to the reactive nature of the fishery management system (Dayton 1998), it would seem that fishery managers would be willing to manage new commercial fishery development proactively. The remaining chapter of this thesis will discuss these results and offer a more proactive solution towards dealing with this potential redundant situation. 


\section{Chapter 6}

Summary of Research Results, Discussion, Recommendations, and Conclusion

\section{Summary of Research Results}

Chapter 1 began with a quote from the U.S. Navy highlighting the possibility for commercial fish species to shift out of the Bering and into the Chukchi and Beaufort Seas due to the warming effects of climate change. Although this report had not been discovered by the writer of this thesis until the late stages of her work, the quote serves as a reinforcement of the purpose of this thesis. As shown in Chapter 2, changes in sea ice, temperature, and marine species assemblages off Alaska in recent years indicate that this global warming/fishery shifts scenario is highly plausible. If this scenario does occur, it is likely to have implications for Alaska Natives residing along the Chukchi Sea, as discussed in Chapter 3. An expansion of fisheries into the Chukchi Sea is important because this sea currently lacks federal FMP's to control exploratory fishing, as shown in Chapter 4. The next stage of the thesis was to explore the current level preparedness and planning for fishery shifts by physical scientists, social scientists, and fishery managers.

In Chapter 5, the results from the ARCUS and ICASS V conference proceedings and informal and formal interviews were presented. The questions posed to the respondents throughout the conferences and interviews pertained to three themes: 1) planning for a reduction of sea ice and distributional shifts of commercially important species into northern latitudes; 2) future fisheries management and proactive development of this management in the Chukchi Sea; and 3) the effects of new 
development on Alaska Natives, and how they could be involved in the management of new resources moving into their region.

Physical scientists at the ARCUS conference and fishery managers in Anchorage and Juneau, Alaska were presented with the research questions regarding planning. When presented with these questions, the two groups displayed a dichotomy in their perceptions regarding the potential effects of climate change in the Arctic. Physical scientists at the ARCUS conference believed that the Arctic will continue to warm and that planning should be done now to prepare for a future ice-free Arctic. In contrast, fishery managers felt that planning for future changes in the Arctic should not be done at the current time. Physical scientists believed that planning should be done by developing new policies to curb greenhouse gas emissions and by planning for the reduction of sea ice and increased commercial development in the Arctic. Fishery managers did not believe that planning should be done to prepare for shifts in fish stocks or for new commercial fisheries development in the Arctic because they believe these shifts will happen gradually and the management system in place will be able to "react" accordingly. Managers believed that if any planning is to be done now, it should be in the research sector.

Fishery managers were also presented with the research questions regarding future fisheries management and proactive management in the Chukchi Sea. The majority of fishery managers stated that any new management would likely be an extension of the fisheries management currently done in the Bering Sea. Fishery managers believed that the reactive management system in place would be sufficient 
to control exploratory fishing, and therefore a proactive approach would not be needed to ensure the sustainability of fish stocks moving into the Chukchi Sea.

Social scientists and fishery managers were presented with research questions regarding the involvement of Alaska Natives in the management of new fisheries moving into the Chukchi Sea. These two groups agreed that Alaska Natives in the Chukchi Sea region are likely to be affected by new commercial fisheries development, and that these effects are likely to be a mix of positives and negatives. Positive effects include gaining employment opportunities and developing new infrastructure in the Arctic. Negative effects include the disruption of whale migration routes and their food web, competition over fishery resources (between Natives and the new commercial fisheries), an increase in vessel noise that changes the distribution of species, pollution discharge, and generally adversely affecting the culture of Chukchi Sea residents. The vast majority of respondents believed that the Community Development Quota (CDQ) program could be used to involve Alaska Natives in the management process of developing new fisheries in the Chukchi Sea, and that all Native communities within fifty miles of the shoreline could be involved in this new management.

Three surprising results emerged from this thesis research: 1) fishery managers do not believe planning should be done to prepare for fisheries shifts into the Chukchi Sea; 2) when given the chance to choose proactive over reactive fisheries management, most fishery managers chose to be reactive by stating they would simply extend the current management of the Bering Sea after exploratory fishing begins; and 3) respondents equated the involvement of Alaska Natives in economic opportunities 
to the involvement of Alaska Natives in making management decisions regarding fishery resources that could shift into the Chukchi Sea in the future. These results will be discussed in the following two sections.

Planning for the Implications of Climate Change in the Chukchi Sea

Fisheries management in the Bering Sea is reactive, rather than proactive in nature. If management is simply extended from the Bering Sea into the Chukchi Sea, fisheries may start too soon, regulations could come too late, and the ecosystem could be significantly affected. This is an entirely new ecosystem, and for once managers have the chance to get fisheries management right — from the beginning. By looking ahead and planning for a situation to occur, the management in that area will go smoother in the long run with benefits to the ecosystem. But how does one plan in the world of fisheries management? Planning is done by being proactive in the development of a new policy or procedure by which fishery resources can be extracted from federal waters in the Chukchi Sea.

What is proactive management? What are the benefits, and most of all, are there models of proactive management upon which to base new management in the Chukchi Sea? The proactive approach recognizes that overfishing can occur quickly within a reactive fisheries management system. Instead of making decisions and taking action in response to crises or problems, fishery managers could do the opposite with a proactive approach by developing management options prior to or immediately following the inception of fishing. The benefits of proactive management are the 
protection of the fish stock, habitat, and the trophic levels of an ecosystem prior to the onset of commercial fisheries development (Cochrane 2002).

There are two models of proactive fisheries management that could be used to shape the development of proactive management in the Chukchi Sea. The first model is the Convention on the Conservation of Antarctic Marine Living Resources (CCAMLR), and the second model is a policy that is currently being developed by the Alaska Department of Fish and Game (ADF\&G) called the "New and Developing Fisheries Policy.”

The Convention on the Conservation of Antarctic Marine Living Resources (CCAMLR) is an agreement that was developed due to concerns over the future implications of commercial fisheries development (in particular a commercial fishery for krill) on the Antarctic ecosystem. Krill is an important resource for the entire Antarctic ecosystem, so it was decided to develop a means to manage the krill fishery in the Southern Ocean. Management was not developed in response to a collapse of the krill fishery; it was developed proactively in anticipation of the future affects of krill removal on the entire ecosystem (CCAMLR 2004; Parkes 2000).

CCAMLR entered into force in 1982 and it not only takes an ecosystem-based management approach but also takes a precautionary approach towards managing fisheries. The ecosystem approach recognizes that the entire Southern Ocean is interlinked, removal of one species could have impacts on 'dependent and related' species within the overall ecosystem. The precautionary approach recognizes that any fisheries management decision must take into account and minimize any long-term adverse impacts of that decision (Young 1998). Precautionary fisheries management 
recognizes that an ecosystem can be harmed via anthropogenic inputs into the ecosystem as well as the extraction of marine species. In theory the precautionary approach ensures that decisions are not made that would have long term adverse affects; it incorporates uncertainty within the fishery into management decisions; it is often used in data-limited situations; it allows for adaptability to new situations; and it ensures that catch limits are set at levels that will not be detrimental to other species (Parkes 2000; Young 1998).

The precautionary approach is useful as a buffer when there is a large amount of uncertainty in the fishery (Charles 1998; Young 1998). Uncertainty would likely arise when the actual stock size is unknown or when a new fishery is developing that lacks a large amount of data upon which to base a sound stock assessment (CCAMLR 2004). Any fish stocks moving into the Chukchi Sea would be residing in a highly uncertain environment and would likely have fluctuating populations. Under the precautionary approach, the larger the uncertainty in a fishery, the more precaution is to be taken (Charles 1998). Therefore any new fisheries development in the Chukchi Sea would likely start off slow and have very low harvest levels that take this uncertainty into account, thus optimizing the benefits coming from Chukchi Sea fisheries in the long run.

The second model of a proactive approach to fisheries management is the "New and Developing Fisheries Policy" that is currently being developed by the Alaska Department of Fish and Game (ADFG 2002). The primary goal of the New and Developing Fisheries Policy is to encourage the development of new fisheries by the industry in a manner that promotes the long-term conservation of the fish stock 
through the use of good scientific management. Some other goals include creating new economic opportunities in Alaska Native communities, encouraging investment into Alaskan processing and fishing operations, and promoting local fishing economies that are self-sustaining in nature (ADFG 2002). This policy is currently being developed by the ADFG, but the policy has not yet been passed and there have been subsequent issues with state funding (ADFG 2004e).

This new ADFG policy can be considered proactive in its approach because it recognizes that a new fishery should not just be opened; rather it should only be opened if based on sound science (ADFG 2002). Within this policy, the parties that wish to develop new fisheries must first prove that a fishery could be developed sustainably. This is done by doing studies on the fish stocks to see if the development would be detrimental to the fish population. In conventional fisheries management, the managers would choose to manage a fish stock only if it could be proven that management was needed (Dayton 1998). However, there has been a recent change within the literature suggesting that managers should not assume that the development of a fishery will not be detrimental to a fish stock. Instead of assuming that the fishery development will not be detrimental to a species, the "Burden of Proof" should be reversed. In theory, by reversing the Burden of Proof, those involved in taking marine resources would have to prove that the fish stock is healthy enough to allow commercial fishing (Dayton 1998). This reversal of the Burden of Proof is inherent in the New and Developing Fisheries Policy.

If commercial fisheries were developed in the Chukchi Sea, a proactive approach would be particularly appropriate due to the large amount of uncertainty 
over the status of the fish stocks moving into the region. Reactive fisheries management often leads to overfishing and is not appropriate for the Chukchi Sea region. Given the rate at which the environment of northern Alaska is changing due to warming temperatures (see Chapter 2), it would be appropriate for fishery managers to plan now for the expansion of commercial fisheries into northern regions.

New proactive fisheries management could be modeled after CCAMLR (with its ecosystem and precautionary approaches) or the ADFG "New and Developing Fisheries Policy" (which is an example of reversing the Burden of Proof). If the New and Developing Fisheries Policy is passed, it will only apply to state waters off Alaska. The NPFMC could develop a similar policy that incorporates the precautionary approach used in CCAMLR, and then the council could apply this policy in federal waters prior to any large-scale fisheries development in the Chukchi Sea. Any policies proactively planned and put in place prior to fisheries expansion would benefit the fish stocks, marine habitat, and the Alaska Natives residing in the Chukchi Sea region.

Future Involvement of Alaska Natives in Fisheries Management in the Chukchi Sea

This thesis research sought answers to how Alaska Natives could be affected by new commercial fisheries development in the Chukchi Sea, and then to how Natives could be involved in the management of resources moving into the Chukchi Sea. In Chapter 3, a clear distinction was drawn between involving Alaska Natives in the management of marine resources moving into the Chukchi Sea, and involving Alaska Natives in economic opportunities that are likely to develop in the Chukchi 
Sea. The involvement of these Natives in economic opportunities could be done with the CDQ program, while the involvement in management aspects could be done with a form of co-management.

Respondents stated that Alaska Natives would likely be affected (positively and/or negatively) by new commercial fisheries development and that Alaska Natives could then be involved in the management of new resources through the use of the Western Alaska CDQ program. However, the CDQ program does not "involve" Alaska Natives in management decisions over fishery resources in the Bering Sea per se (Schreiber 2001). In fact, respondents equated the two types of involvement (e.g. involving Alaska Natives in economic opportunities, and involving them in the management). However, these two types of involvement are two separate concepts in fisheries management.

Alaska Natives residing along the Bering Sea are currently involved in the economic opportunities of fisheries development through the use of the Western Alaska CDQ program. The intent of the CDQ program was to involve underdeveloped coastal communities of the Bering Sea and Aleutian Islands in economic opportunities that they had historically been shut out of, and not as a way to involve these communities in the management aspects of developing fisheries (NRC 1999).

However, Alaska Natives can be involved in the management of resources through co-management agreements. Co-management is a power-sharing agreement between the government and local communities that allows local communities to make management decisions (Pinkerton 1989). If fisheries were developed in the Chukchi 
Sea, it would seem logical to actually empower the communities by developing comanagement agreements with these communities instead of simply allocating them a TAC percentage as under the CDQ program. For example, co-management agreements for Eskimo whaling have been successful in the past, ${ }^{16}$ so co-management of fisheries could be successful in the future if communities are truly given the management authority over fishery resources moving into the Chukchi Sea. The following is a list of recommendations that could serve as the next steps to be taken to prepare for shifting fisheries due to climate change.

\section{$\underline{\text { Recommendations }}$}

1. Fishery managers should start thinking about the potential management implications of shifting fisheries

2. Fishery managers and scientists should conduct some long-term forecasting and planning to anticipate the changes that may occur in fisheries due to climate change

3. Scientists should start doing baseline studies of fishery resources in the Chukchi Sea, and then continue to monitor this sea in the coming years

4. Fishery managers should adopt an experimental or adaptive approach to fishery management actions in the Chukchi Sea

5. Fishery managers should design and implement fishery management institutions in the Chukchi Sea that will recognize shifts in the ranges of species, abundances, and accessibility

\footnotetext{
${ }^{16}$ For more details on a successful co-management agreement in Alaska, see Freeman (1989).
} 


\section{Conclusion}

This thesis research has confirmed the first impression of the author that fishery managers are not prepared, and are not planning, for the expansion of commercial fisheries into the Arctic. According to the physical scientists interviewed, global warming is a very real issue that could result in significant implications for commercial development in the Arctic. The Navy has formed an unambiguous position on the potential for new commercial fisheries development in the Chukchi and Beaufort Seas. The Navy's position on climate change and the need for strategic planning has gone unheeded by fishery managers, and when these managers were presented with the global warming/fishery shifts scenario many replied that the scenario was too far in the future for current fishery managers to think about. However, the United States' largest commercial fisheries reside in the Bering Sea, and this thesis has proven that fisheries could develop in the Chukchi Sea due to further changes in climate.

In the future, if fishery managers "react" to new fisheries development by extending the Bering Sea management into the Chukchi Sea, the fish stocks and the ecosystem could be adversely affected by fisheries that develop too soon. If these fisheries develop, managers may have to quickly develop new FMP's for the region, while accommodating the desires of Alaska Natives that either want to be involved in making management decisions or want to be involved in this new economic opportunity. Fishery managers could appropriately plan for this new development by drafting a proactive plan that addresses when, how, and where fishing could develop in the Chukchi Sea, and who can be involved in fishing and in new management 
decisions. Regardless of whether the recent climate changes witnessed by Alaska Natives and physical scientists are due to natural or anthropogenic causes, it is more important now for scientists and fishery managers to anticipate what lies ahead rather than react to changes as they unfold. 


\section{Appendix A}

National Standards for fishery conservation and management mandated by the MSFCMA ( $\$ 206 c, 301)$. Fishery Management Plans and regulations must be consistent with the following national standards:

1. Conservation and management measures shall prevent overfishing while achieving, on a continuing basis, the optimum yield from each fishery for the United States fishing industry.

2. Conservation and management measures shall be based upon the best scientific information available.

3. To the extent practicable, an individual stock of fish shall be managed as a unit throughout its range, and interrelated stocks of fish shall be managed as a unit or in close coordination.

4. Conservation and management measures shall not discriminate between residents of different States. If it becomes necessary to allocate or assign fishing privileges among various United States fishermen, such allocation shall be (A) fair and equitable to all such fishermen; (B) reasonably calculated to promote conservation; and (C) carried out in such manner that no particular individual, corporation, or other entity acquires an excessive share of such privileges.

5. Conservation and management measures shall, where practicable, consider efficiency in the utilization of fishery resources; except that no such measure shall have economic allocation as its sole purpose.

6. Conservation and management measures shall take into account and allow for variations among, and contingencies in, fisheries, fishery resources, and catches.

7. Conservation and management measures shall, where practicable, minimize costs and avoid unnecessary duplication.

8. Conservation and management measures shall, consistent with the conservation requirements of this chapter (including the prevention of overfishing and rebuilding of overfished stocks), take into account the importance of fishery resources to fishing communities in order to (A) provide for the sustained participation of such communities, and (B) to the extent practicable, minimize adverse economic impacts on such communities.

9. Conservation and management measures shall, to the extent practicable, (A) minimize bycatch and $(B)$ to the extend bycatch cannot be avoided, minimize the mortality of such bycatch.

10. Conservation and management measures shall, to the extent practicable, promote the safety of human life at sea. 
Bibliography

Alaska Department of Fish and Game (ADFG). 2002. A Plan for the Development of New Fisheries in Alaska. Draft Policy Paper, 11 October 2002. Alaska Department of Fish and Game. 17pp.

Alaska Department of Fish and Game (ADFG). 2004a. Board of Fisheries information webpage. Accessed 4 February 2004; Available at: http://www.state.ak.us/local/akpages/FISH.GAME/boards/fishinfo.

Alaska Department of Fish and Game (ADFG). 2004b. Mission Statement: Division of Subsistence. Accessed 4 February 2004; Available at: http://www.subsistence.adfg.state.ak.us.

Alaska Department of Fish and Game (ADFG). 2004c. Division of Commercial Fisheries 2004 Overview. Accessed 10 April 2004; Available at: http://www.cf.adfg.state.ak.us/geninfo/about/budget/04overview.pdf.

Alaska Department of Fish and Game (ADFG). 2004d. Division of Commercial Fisheries homepage. Accessed 10 April 2004; Available at: http://www.cf.adfg.state.ak.us.

Alaska Department of Fish and Game (ADFG). 2004e. Board of Fisheries news story on the Draft Developing Fisheries Policy (to be withdrawn). Accessed 24 July 2004; Available at: http://www.cf.adfg.state.ak.us/fishinfo/news/devfishwdraw.php.

Alley, R.B., J. Marotzke, W.D. Nordhaus, J.T. Overpeck, D.M. Peteet, R.A. Pielke, Jr., R.T. Pierrehumbert, P.B. Rhines, T.F. Stocker, L.D. Talleyand J.M. Wallace. 2003. Abrupt climate change. Science 299: 2005-2010.

Anungazuk, H. 2004. Many shades of change. In the Session: Globalization and Self-Determination: Assessing Challenge and Change in the Arctic. Presentation given at the $5^{\text {th }}$ International Congress of Arctic Social Sciences (ICASS V) conference, Fairbanks, Alaska, 21 May 2004.

Babaluk, J. A., J. D. Reist, J. D. Johnson, and L. Johnson. 2000. First records of sockeye (Oncorhynchus nerka) and pink salmon (O. gorbuscha) from Banks Island and other records of Pacific salmon in Northwest Territories, Canada. Arctic 53: 161-64.

Benson, A.J. and A.W. Trites. 2002. Ecological effects of regime shifts in the Bering Sea and eastern North Pacific Ocean. Fish and Fisheries 3: 95-113. 
Bering Sea Impact Study (BESIS). 1997. Bering Sea Impacts Study (BESIS): The impacts of global climate change in the Bering Sea region. An assessment conducted by the International Arctic Science Committee under its Bering Sea Impacts Study (BESIS). Results of a Workshop in Girdwood, Alaska 18-21 September 1996. Oslo: International Arctic Science Committee. 41pp.

Bjorgo, E., O.M. Johannessen, and M.W. Miles. 1997. Analysis of merged SMMRSSMI time series of Arctic and Antarctic sea ice parameters 1978-1995. Geophysical Research Letters 24 (4): 413-416.

Bloom, E. 1999. Establishment of the Arctic Council. 93 AJIL 712.

Bosworth, R. 1995. Biology, politics, and culture in the management of subsistence hunting and fishing: An Alaskan case history. In Human Ecology and Climate Change: People and Resources in the Far North, edited by D.L. Peterson and D.R. Johnson. Washington, D.C.: Taylor and Francis, pp. 245-259.

Brander, K. 1997. Effects of climate change on cod (Gadus morhua) stocks. In Global Warming: Implications for Freshwater and Marine Fish, ed. C.M. Wood and D.G. McDonald, 255-78. Cambridge: Cambridge UP.

Brigham-Grette, J. 2001. New perspectives on Beringian Quaternary paleogeography, stratigraphy, and glacial history. Quaternary Science Reviews 20: 15-24.

Brigham-Grette, J., and D. Hopkins. 1995. Emergent marine record and paleoclimate of the last interglaciation along the Northwest Alaskan Coast. Quaternary Research 43: 159-173.

Brodeur, R.D., M.T. Wilson, G.E. Walters, and I.V. Melnikov. 1999. Forage fishes in the Bering Sea: Distribution, species associations, and biomass trends. In Dynamics of the Bering Sea: A summary of physical, chemical, and biological characteristics, and a synopsis of research on the Bering Sea, North Pacific Marine Science Organization (PICES), University of Alaska Sea Grant, AKSG-99-03, Fairbanks, Alaska, USA. pp. 509-536.

Buckley, T.W., A. Greig, J. Ianelli, P. Livingston, and G. Walters. 2001. Spatial distribution and ontogenic movement of walleye pollock in the eastern Bering Sea. A paper presented at the North Pacific Marine Science Organization (PICES), Victoria, B.C., Canada, October 5-13, 2001. 7 pp. 
Callaway, D. 1998. Effects of Climate Change on Subsistence Communities in Alaska. In Assessing the Consequences of Climate Change for Alaska and the Bering Sea Region. Proceedings of a Workshop at the University of Alaska, Fairbanks. 29-30 October 1998, edited by Gunter Weller and Patricia Anderson. Center for Global Change and Arctic System Research, University of Alaska Fairbanks.

Charles, A.T. 1998. Fisheries in transition. In Ocean Yearbook 13. University of Chicago. pp. 15-37.

Cochrane, K.L. 2002. Chapter 1: Fisheries Management. In K.L. Cochrane (ed.), A fishery manager's guidebook. Management measures and their application. FAO Fisheries Technical Paper. No. 424. Rome, FAO. 231pp.

Comiso, J.C. 2001. Satellite-observed variability and trend in sea-ice extent, surface temperature, albedo, and clouds in the Arctic. Ann. Glaciol. 33: 457-473.

Comiso, J. 2002. A rapidly declining perennial sea ice cover in the Arctic. Geophysical Research Letters 29 (20): 1956, doi: 10.1029/2002GL015650.

Comiso, J. 2003. Warming trends in the Arctic from clear sky satellite observations. J. of Climate 16: 3498-3510.

Congressional Research Service (CRS). 1997. Fisheries and Marine Mammals: most recent developments (9/05/97). Accessed 22 March 2004; Available online at: http://www.netpets.com/fish/legarchives/997mo.html.

Convention on the Conservation of Antarctic Marine Living Resources (CCAMLR). 2004. Chapter 2: Understanding CCAMLR's Approach to Management. Accessed 30 March 2004; Available at: http://www.ccamlr.org/pu/E/pubs/am/p2.htm.

Corten, A. 2001. Northern distribution of North Sea herring as a response to high water temperatures and/or low food abundance. Fisheries Research 50: 189204.

Crawshaw, L. and C.S. O’Connor. 1996. Behavioral compensation for long-term thermal change. In Global Warming: Implications for Freshwater and Marine Fish, ed. C.M. Wood and D.G. McDonald, 351-76. Cambridge: Cambridge UP.

Dayton, P. 1998. Reversal of the burden of proof in fisheries management. Science 279: 821-822. 
Dixon, K.W., T.L. Delworth, T.R. Knutson, M.J. Spelman, and R.J. Stouffer. 2003. A comparison of climate change simulations produced by two GFDL coupled climate models. Global and Planetary Change 37: 81-102.

Doyle, A. 2004. Arctic climate change is human rights abuse- Inuit. Online articleABC news. Accessed 11 December 2003; Available online at: http://abcnews.go.com/wire/US/reuters20031210_368.html.

Fox, S. 2002. These are things that are really happening: Inuit perspectives on the evidence and impacts of climate change in Nunavut. In The Earth is Faster Now: Indigenous Observations of Arctic Environmental Change, edited by I. Krupnik and D. Jolly. Fairbanks, AK: Arctic Research Consortium of the United States. pp. 13-53.

Freeman, M.M.R. 1989. The Alaska Eskimo Whaling Commission: successful comanagement under extreme conditions. In Co-operative management of local fisheries: new directions for improved management and community development, edited by E. Pinkerton. Vancouver: University of British Columbia Press, pp. 137-153.

Freese, D.H. 2000. The Consumptive Use of Wild Species in the Arctic: challenges and opportunities for ecological sustainability. A paper written for $W W F$ Canada and WWF International Arctic Programme.

Haley, S. 2004. Institutional assets for community and regional resilience: managing resource development and adapting to climate change in the Arctic. In the Session: Effective Local Institutions for Collective Action in Arctic Communities. Presentation given at the $5^{\text {th }}$ International Congress of Arctic Social Sciences (ICASS V) conference, Fairbanks, Alaska, 21 May 2004.

Hare, S.R. and R.C. Francis. 1995. Climate change and salmon production in the Northeast Pacific Ocean. p. 357-372 in: R.J. Beamish (ed.) Climate Change and Northern Fish Populations. Can. spec. Publ. Fish. Aquat. Sci. 121.

Hare, S.R. and N.J. Mantua. 2000. Empirical evidence for North Pacific regime shifts in 1977 and 1989. Progress in Oceanography 47: 103-145.

Henshaw, A. 2004. Toponymy and climate: embedding local knowledge within climate change discourses. In the Session: Locating Circumpolar Environmental Change: From Global to Local. Presentation given at the $5^{\text {th }}$ International Congress of Arctic Social Sciences (ICASS V) conference, Fairbanks, Alaska, 19 May 2004.

Hunt, G.L. Jr., P.J. Stabeno, G. Walters, E. Sinclair, R.D. Brodeur, J.M. Napp, and N.A. Bond. 2002. Climate change and control of the southeastern Bering Sea pelagic ecosystem. Deep-Sea Research II 49: 5821-5853. 
Intergovernmental Panel on Climate Change. 1997. IPCC Special Report on the Regional Impacts of Climate Change: An Assessment of Vulnerability. Edited by R.T. Watson, M.C. Zinyowera, and R.H. Moss. Cambridge University Press, Cambridge, United Kingdom and New York, NY, USA, 517 pp.

Intergovernmental Panel on Climate Change. 2001. Climate Change 2001: Impacts, Adaptation, and Vulnerability. Contribution of Working Group II to the Third Assessment Report of the Intergovernmental Panel on Climate Change. Edited by McCarthy, J.J., O.F. Canziani, N.A. Leary, D.J. Dokken, and K.S. White. Cambridge University Press, Cambridge, United Kingdom and New York, NY, USA, 1032 pp.

Jones, P.D., M. New, D.E. Parker, S. Martin, and I.G. Rigor. 1999. Surface air temperature and its changes over the past 150 years. Reviews of Geophysics 37 (2): 173-199.

Krupnik, I. 2000a. Humans in the Bering Strait Region: responses to environmental change and implications for the future. In: Impacts of Changes in Sea Ice and Other Environmental Parameters in the Arctic. Edited by Henry Huntington. Final Report of the Marine Mammal Commission Workshop, Girdwood, Alaska, 15-17 February 2000.

Krupnik, I. 2000b. Native perspectives on climate and sea ice changes. In: Impacts of Changes in Sea Ice and Other Environmental Parameters in the Arctic. Edited by Henry Huntington. Final Report of the Marine Mammal Commission Workshop, Girdwood, Alaska, 15-17 February 2000.

Krupnik, I. and D. Jolly (eds.). 2002. The Earth is Faster Now: Indigenous Observations of Arctic Environmental Change. Fairbanks, Alaska: Arctic Research Consortium of the United States. 384 pp.

Kruse, G. 1998. Salmon run failures in 1997-1998: A link to anomalous ocean conditions? Alaska Fishery Research Bulletin 5 (1): 55-63.

Laevastu, T. 1993. Marine Climate, Weather and Fisheries. New York: Halsted Press.

Laughlin, W.S. 2002. Aleuts: Survivors of the Bering Land Bridge. Wadsworth/Thompson Learning, Belmont, CA. 151pp.

Levitus, S., J.I. Antonov, T.P. Boyer, and C. Stephens. 2000. Warming of the world ocean (supplemental material). Science 287: 2225-2229. 
Loeng, H. 2001. Possible climate impacts on marine ecosystems. Invited Presentation at the Arctic Climate Impact Assessment Modeling and Scenarios Workshop. January 29-31, 2001. Stockholm, Sweden. Accessed 27 July 2004; Available at: http://www.acia.uaf.edu/PDFs/Stockholm_final.pdf.

Lonner, T.D. 1986. Subsistence as an Economic System in Alaska: Theoretical Observations and Management Implications. In S.J. Langdon (editor) Contemporary Alaskan Native Economies. University Press of America, Lanham and London, pp.15-28.

Magnuson, J.J. 2002. A future of adapting to climate change and variability. American Fisheries Society Symposium 32: 273-282.

Magnuson Stevens Fishery Conservation and Management Act (MSFCMA), Public Law 94-265, Amended 11 October 1996.

Mann, M.E. 2003. The value of multiple proxies. Science 297: 1481-1482.

Mantua, N. J. and P. W. Mote. 2002. Uncertainty in scenarios of human-caused climate change. American Fisheries Society Symposium 32: 263-272.

Maslanik, J.A., M.C. Serreze, and T. Agnew. 1999. On the record reduction in 1998 Western Arctic sea ice cover. Geophysical Research Letters 26(13): 19051908.

National Marine Fisheries Service (NMFS). 2003. Annual Report to Congress on the Status of U.S. Fisheries- 2002. U.S. Dep. Commer., NOAA/NMFS Report. $156 \mathrm{pp}$.

National Marine Fisheries Service (NMFS). 2004a. NMFS Strategic Plan for Fisheries Research. U.S. Dep. Commer., NOAA Tech. Memo. NMFS F/SPO$61,148 \mathrm{p}$.

National Marine Fisheries Service (NMFS). 2004b. The Convention on the Conservation and Management of the Pollock Resources in the Central Bering Sea: Brief Description. Accessed 29 June 2004; Available at http://www.afsc.noaa.gov/refm/cbs/convention_description.htm.

National Oceanic and Atmospheric Administration (NOAA). 2004. Proxies used in determining climate change. Accessed 19 July 2004; Available at: http://www.ngdc.noaa.gov/paleo/primer_proxy.html.

National Research Council (NRC). 1999. The Community Development Quota Program in Alaska. Washington, D.C.: National Academy Press, 215 pp. 
National Research Council (NRC). 1996. The Bering Sea Ecosystem. Washington, D.C.: National Academy Press, 307pp.

Niebauer, H.J., N.A. Bond, L.P. Yakunin, and V.V. Plotnikov. 1999. An update on the climatology and sea ice of the Bering Sea. In Dynamics of the Bering Sea, pp. 29-59.

Norton, D.W. 2002. Coastal sea ice watch: private confessions of a convert to indigenous knowledge. In The Earth is Faster Now: Indigenous Observations of Arctic Environmental Change, edited by I. Krupnik and D. Jolly. Fairbanks, AK: Arctic Research Consortium of the United States. pp. 127-155.

Nuttall, M. 2001. Indigenous peoples and climate change research in the Arctic. Indigenous Affairs 4: 27-33.

Oiestad, V. 1994. Historic changes in cod stocks and cod fisheries: northeast arctic cod. ICES Mar. Sci. Symp. 198: 17-30.

Parkes, G. 2000. Precautionary fisheries management: the CCAMLR approach. Marine Policy 24: 83-91.

Parsons, D.J. 1991. Planning for climate change in national parks and other natural areas. The Northwest Environmental Journal 7: 255-269.

Pew Oceans Commission (Pew Report). 2002. Managing Marine Fisheries in the United States: Proceedings of the Pew Oceans Commission Workshop on Marine Fishery Management, Seattle, Washington, 18-19 July 2001. Pew Oceans Commission, Arlington, Virginia, 74pp.

Pinkerton, E. 1989. Introduction: Attaining better fisheries management through comanagement- prospects, problems, and propositions. In Co-operative management of local fisheries: new directions for improved management and community development, edited by E. Pinkerton. Vancouver: University of British Columbia Press, pp. 3-33.

Quinn, T. J., and R. P. Marshall. 1989. Time series analysis: quantifying variability and correlation in Alaska salmon catches and environmental data. Canadian Special Publications in Fisheries and Aquatic Science 108: 67-80.

Ray, D.J. 1975. The Eskimos of Bering Strait, 1650-1898. Seattle and London: University of Washington Press. 305pp.

Rosentrater, L. and A.E. Ogden. 2003. Buying Time: A User's Manual for Building Resistance and Resilience to Climate Change in Natural Systems, Chapter 4: Arctic. World Wildlife Foundation Climate Change Program, pp. 95-121. 
Rothrock, D., Y. Yu, and G. Maykut. 1999. The thinning of the Arctic ice cover. Geophysical Research Letters 26: 3469-3472.

Schreiber, D.K. 2001. Co-management without involvement: the plight of fishing communities. Fish and Fisheries 2: 376-384.

Schumacher, J.D., N.A. Bond, R.D. Brodeur, P.A. Livingston, J.M. Napp, and P.J. Stabeno. 2003. Climate change in the southeastern Bering Sea and some consequences for biota. In Hempel, G. and K. Sherman (eds.): Large Marine Ecosystems of the World- Trends in Exploitation, Protection, and Research. Amsterdam: Elsevier Science, 423pp.

Serreze, M.C. 2004. Background on sea ice and Arctic climate. A presentation given at the Arctic Research Consortium of the United States $16^{\text {th }}$ Annual Meeting and Arctic Forum, Washington, D.C., 13 May 2004.

Stabeno, P. J., Bond, N. A., Kachel, N. B., Salo, S. A., and Schumacher, J. D. 2001. On the temporal variability of the physical environment over the southeastern Bering Sea. Fisheries Oceanography 10: 81-98.

Stabeno, P.J. and J.E. Overland. 2001. Bering Sea shifts toward an earlier spring transition. $\operatorname{EOS} 82$ (29): 317-321.

Steele, J.H. 1996. Regime shifts in fisheries management. Fisheries Research 25: $19-23$.

Stirling, I. 1997. The importance of polynyas, ice edges, and leads to marine mammals and birds. J. Marine Systems 10: 9-21.

Stirling, I., N. Lunn, and J. Iacozza. 1999. Long-term trends in the population ecology of polar bears in western Hudson Bay in relation to climate change. Arctic 52: 294-306.

Strickland, R.M. and T. Sibley. 1984. Projected effects of CO2-induced climate change on the Alaska walleye pollock (Theragra chalcogramma) fishery in the eastern Bering Sea and Gulf of Alaska. University of Washington, Seattle, Wash. FRI-UW-8411. 112pp.

Thorpe, N., S. Eyegetok, N. Hakongak, and the Kitikmeot Elders. 2002. Nowadays it is not the same: Inuit Qaujimajatuqangit, climate and caribou in the Kitikmeot region of Nunavut, Canada. In The Earth is Faster Now: Indigenous Observations of Arctic Environmental Change, edited by I. Krupnik and D. Jolly. Fairbanks, AK: Arctic Research Consortium of the United States. pp. 201-239. 
Tynan, C.T. and D. P. DeMaster. 1997. Observations and predictions of Arctic climate change: potential effects on marine mammals. Arctic 50 (4): 308-322.

United States Commission on Ocean Policy (USCOP). 2004. Preliminary Report of the U.S. Commission on Ocean Policy, Governors' Draft, Washington, D.C., April, 2004.

United States Geological Survey (USGS). 2004. Last Interglacial: Timing and Environment (LITE). Vegetation and paleoclimate of the last interglacial period, central Alaska. USGS Earth Surface Processes. Accessed 22 July 2004; Available at: http://climchange.cr.usgs.gov/info/lite/alaska/alaska.html.

Vinnikov, K.Y., A. Robock, R. Stouffer, J. Walsh, C. Parkinson, D. Cavalieri, J. Mitchell, D. Garrett, and V. Zakharov. 1999. Global warming and northern hemisphere sea ice extent. Science 286(5446): 1934-1937.

Von Glahn, G. 1996. Law Among Nations: An introduction to public international law. $7^{\text {th }}$ ed. Boston, MA: Allyn \& Bacon. 734 pp.

Weller, G. 2000. Climate Change and its impacts on the arctic environment. In: Impacts of Changes in Sea Ice and Other Environmental Parameters in the Arctic. Edited by Henry Huntington. Final Report of the Marine Mammal Commission Workshop, Girdwood, Alaska, 15-17 February 2000.

Whitney, Bradley, \& Brown, Inc. (preparers). 2001. Naval Operations in an Ice-Free Arctic. Final Report of the Naval Operations in an Ice-Free Arctic Symposium, conducted 17-18 April 2001 by the Office of Naval Research, Naval Ice Center, Oceanographer of the Navy, and the Arctic Research Commission, 70pp. Accessed 14 July 2004; Available at: http://www.natice.noaa.gov/icefree/FinalArcticReport.pdf.

Witherell, D., C. Pautzke, and D. Fluharty. 2000. An ecosystem-based approach for Alaska groundfish fisheries. ICES Journal of Marine Science 57: 771-777.

Wohlforth, C. 2004. The whale and the supercomputer: on the northern front of climate change. New York: North Point Press. 322 pp.

Wyllie-Echeverria, T. 1995. Sea-ice conditions and the distribution of walleye pollock (Theragra chalcogramma) on the Bering and Chukchi Sea Shelf. In. Climate Change and Northern Fish Populations. Ed. R.J. Beamish. Can. Spec. Publ. Fish. Aquat. Sci. 121: 131-13

Wyllie-Echeverria, T. and W.S. Wooster. 1998. Year-to-year variations in Bering Sea ice cover and some consequences for fish distributions. Fisheries Oceanography 7 (2): 159-170. 
Young, O.R. 1998. Institutional uncertainties in international fisheries management. Fisheries Research 37: 211-224.

Young, O.R. 1982. The political economy of fish: the Fishery Conservation and Management Act of 1976. Ocean Development and International Law Journal 10(3/4): 199-205, 210-211, 214-225, 234-245, 256-260. 